\title{
End-On and Side-On Peroxo Derivatives of Non-Heme Iron Complexes with Pentadentate Ligands: Models for Putative Intermediates in Biological Iron/Dioxygen Chemistry
}

\author{
Gerard Roelfes, ${ }^{\dagger}$ Vladislav Vrajmasu, ${ }^{\ddagger}$ Kui Chen, ${ }^{\S}$ Raymond Y. N. Ho, ${ }^{\S}$ Jan-Uwe Rohde, ${ }^{\S}$ \\ Charon Zondervan, ${ }^{\dagger}$ Rene M. la Crois, ${ }^{\dagger}$ Ebe P. Schudde, ${ }^{\dagger}$ Martin Lutz," Anthony L. Spek," \\ Ronald Hage, ${ }^{\perp}$ Ben L. Feringa, ${ }^{*, \dagger}$ Eckard Munck, ${ }^{*, \neq}$ and Lawrence Que, Jr. ${ }^{*, \S}$ \\ Department of Organic and Molecular Inorganic Chemistry, Stratingh Institute, University of \\ Groningen, Nijenborgh 4, 9747 AG Groningen, The Netherlands, Department of Chemistry, \\ Carnegie Mellon University, Pittsburgh, Pennsylvania 15213, Department of Chemistry and \\ Center for Metals in Biocatalysis, University of Minnesota, Minneapolis, Minnesota 55455, \\ Crystal and Structural Chemistry, Bijvoet Center for Biomolecular Research, Utrecht University, \\ Padualaan 8, 3584 CH Utrecht, The Netherlands, and Unilever Research and Development \\ Vlaardingen, Olivier van Noortlaan 120, 3133 AT Vlaardingen, The Netherlands
}

Received January 21, 2003

\begin{abstract}
Mononuclear iron(III) species with end-on and side-on peroxide have been proposed or identified in the catalytic cycles of the antitumor drug bleomycin and a variety of enzymes, such as cytochrome P450 and Rieske dioxygenases. Only recently have biomimetic analogues of such reactive species been generated and characterized at low temperatures. We report the synthesis and characterization of a series of iron(II) complexes with pentadentate N5 ligands that react with $\mathrm{H}_{2} \mathrm{O}_{2}$ to generate transient low-spin $\mathrm{Fe}^{\mathrm{III}}-\mathrm{OOH}$ intermediates. These intermediates have low-spin iron(III) centers exhibiting hydroperoxo-to-iron(III) charge-transfer bands in the 500-600-nm region. Their resonance Raman frequencies, $v_{0-0}$, near $800 \mathrm{~cm}^{-1}$ are significantly lower than those observed for high-spin counterparts. The hydroperoxo-to-iron(III) charge-transfer transition blue-shifts and the $v_{0-0}$ of the $\mathrm{Fe}-\mathrm{OOH}$ unit decreases as the $\mathrm{N} 5$ ligand becomes more electron donating. Thus, increasing electron density at the low-spin $\mathrm{Fe}(\mathrm{III})$ center weakens the $\mathrm{O}-\mathrm{O}$ bond, in accord with conclusions drawn from published DFT calculations. The parent $\left[(\mathrm{N} 4 \mathrm{Py}) \mathrm{Fe} \mathrm{e}^{\prime \prime \prime}\left(\eta^{1}-\mathrm{OOH}\right)\right]^{2+}(1 \mathrm{a})$ ion in this series (N4Py $=N, \mathrm{~N}$-bis(2-pyridylmethyl)- $\mathrm{N}$-bis(2-pyridyl)methylamine) can be converted to its conjugate base, which is demonstrated to be a high-spin iron(III) complex with a side-on peroxo ligand, [(N4Py)Fe"' $\left.\left(\eta^{2}-\mathrm{O}_{2}\right)\right]^{+}(\mathbf{1 b})$. A detailed analysis of $\mathbf{1 a}$ and $\mathbf{1 b}$ by EPR and Mössbauer spectroscopy provides insights into their electronic properties. The orientation of the observed ${ }^{57} \mathrm{Fe}$ A-tensor of $1 \mathrm{a}$ can be explained with the frequently employed Griffith model provided the rhombic component of the ligand field, determined by the disposition of the hydroperoxo ligand, is $45^{\circ}$ rotated relative to the octahedral field. EXAFS studies of 1a and $\mathbf{1 b}$ reveal the first metrical details of the iron-peroxo units in this family of complexes: [(N4Py)Fe $\left.\mathrm{Fill}^{\mathrm{II}}\left(\eta^{1}-\mathrm{OOH}\right)\right]^{2+}$ has an $\mathrm{Fe}-\mathrm{O}$ bond of $1.76 \AA$, while $\left[(\mathrm{N} 4 \mathrm{Py}) \mathrm{Fe} \mathrm{el}^{\mathrm{II}}\left(\eta^{2}-\mathrm{O}_{2}\right)\right]^{+}$has two $\mathrm{Fe}-\mathrm{O}$ bonds of $1.93 \AA$, values which are in very good agreement with results obtained from DFT calculations.
\end{abstract}

Mononuclear iron(III) peroxide species are implicated as intermediates in the mechanisms of oxygen activating

* Authors to whom correspondence should be addressed. E-mail: que@chem.umn.edu (L.Q.); b.1.feringa@chem.rug.nl (B.L.F.); emunck@ cmu.edu (E.M.)

University of Groningen.

$\doteqdot$ Carnegie Mellon University.

$\S$ University of Minnesota.

"Utrecht University.

${ }^{\perp}$ Unilever Research and Development Vlaardingen.

10.1021/ic034065p CCC: $\$ 25.00$ C 2003 American Chemical Society Published on Web 03/19/2003 biomolecules such as cytochrome $\mathrm{P} 450,{ }^{1}$ heme oxygenase ${ }^{2}$ the antitumor drug bleomycin, ${ }^{3}$ and Rieske dioxygenases, ${ }^{4,5}$ as well as superoxide reductases from anaerobic bacteria. ${ }^{6-9}$ Experimental evidence for some of these intermediates has

(1) Sono, M.; Roach, M. P.; Coulter, E. D.; Dawson, J. H. Chem. Rev. 1996, 96, 2841-2887.

(2) Ortiz de Montellano, P. R. Acc. Chem. Res. 1998, 31, 543-549.

(3) Burger, R. M. Struct. Bonding 2000, 97, 287-303.

Inorganic Chemistry, Vol. 42, No. 8, 2003 
been obtained. Cryoreduction of the $\mathrm{O}_{2}$ adducts of cytochrome $\mathrm{P} 450$ and heme oxygenase affords low-spin $\mathrm{Fe}^{\mathrm{III}}$ $\left(\eta^{1}-\mathrm{OOH}\right)$ species observed by EPR and ENDOR, which upon warming give rise to their respective oxidation products. ${ }^{10-12}$ Activated bleomycin, the active form of the antitumor drug iron bleomycin (Fe-BLM) ${ }^{13}$ has been established to be a low-spin $\mathrm{Fe}^{\mathrm{III}}\left(\eta^{1}-\mathrm{OOH}\right)$ intermediate, ${ }^{14-16}$ which is thought to be responsible for its DNA cleavage activity. ${ }^{17}$ The reaction of superoxide reductase with superoxide affords a transient purple intermediate, which appears likely to be a peroxo species. ${ }^{6,7,9}$ Very recently, the crystal structure of a ternary enzyme-substrate $-\mathrm{O}_{2}$ complex of naphthalene dioxygenase has been solved to reveal a sideon bound $\mathrm{O}_{2}$ to the active site iron, ${ }^{5 \mathrm{~b}}$ providing the first evidence for such an $\mathrm{O}_{2}$ binding mode in an iron enzyme.

Model complexes have played an important role in enhancing our understanding of such iron-peroxo species. In early efforts to model Fe-BLM, Mascharak and co-workers designed the PMAH ligand (Scheme 1), ${ }^{18,19}$ which closely matched the ligand environment around the iron center. Like Fe-BLM, Fe ${ }^{\mathrm{II}} \mathrm{PMA}$ reacts with $\mathrm{O}_{2}$ to generate a low-spin iron(III) intermediate with EPR parameters nearly identical to those of activated BLM. However, no direct spectroscopic

(4) Que, L., Jr.; Ho, R. Y. N. Chem. Rev. 1996, 96, 2607-2624.

(5) (a) Wolfe, M. D.; Parales, J. V.; Gibson, D. T.; Lipscomb, J. D. J. Biol. Chem. 2001, 276, 1945-1953. (b) Karlsson, A.; Parales, J. V. Parales, R. E.; Gibson, D. T.; Eklund, H.; Ramaswamy, S. Science 2003, 299, 1039-1042.

(6) Coulter, E. D.; Emerson, J. P.; Kurtz, D. M., Jr.; Cabelli, D. E. J. Am. Chem. Soc. 2000, 122, 11555-11556.

(7) Lombard, M.; Houée-Levin, C.; Touati, D.; Fontecave, M.; Nivière, V. Biochemistry 2001, 40, 5032-5040.

(8) Clay, M. D.; Jenney, F. E., Jr.; Hagedoorn, P. L.; George, G. N.; Adams, M. W. W.; Johnson, M. K. J. Am. Chem. Soc. 2002, 124, 788-805.

(9) Mathé, C.; Mattioli, T. A.; Horner, O.; Lombard, M.; Latour, J.-M.; Fontecave, M.; Nivière, V. J. Am. Chem. Soc. 2002, 124, 4966-4967.

(10) Davydov, R. M.; Yoshida, T.; Ikeda-Saito, M.; Hoffman, B. M. J. Am. Chem. Soc. 1999, 121, 10656-10657.

(11) Davydov, R.; Macdonald, I. D. G.; Makris, T. M.; Sligar, S. G.; Hoffman, B. M. J. Am. Chem. Soc. 1999, 121, 10654-10655.

(12) Davydov, R.; Makris, T. M.; Kofman, V.; Werst, D. E.; Sligar, S. G.; Hoffman, B. M. J. Am. Chem. Soc. 2001, 123, 1403-1415.

(13) Abbreviations used: bppa $=N, N$-bis[6-(pivaloylamino)pyridyl-2methyl]pyridyl-2-methylamine; $\mathrm{BLM}=$ bleomycin; bztpen $=N$-benzyl- $N, N^{\prime}, N^{\prime}$-tris(2-pyridylmethyl)-1,2-diaminoethane; EDTA = ethylenediaminetetraacetate; EFG = electric field gradient; EXAFS = extended X-ray absorption fine structure; N4Py $=N, N$-bis(2-pyridylmethyl)- $N$-bis(2-pyridyl)methylamine; OEP $=$ octaethylporphin dianion; oxyHr, oxyhemerythrin; $\mathrm{PMAH}=2-\left(2^{\prime}, 5^{\prime}\right.$-diazapentyl $)-5$ bromopyrimidine-6-carboxylic acid $N$-[2-(4'-imidazolyl)ethyl]amide; Py5 $=2,6$-bis (methoxy $($ di $(2$-pyridyl $))$ methyl $)$ pyridine; $\mathrm{pz}=$ pyrazole; SCE $=$ saturated calomel electrode; $\mathrm{SOR}=$ superoxide reductase; TACN $=1,4,7$-triazacyclononane; TACNPy2 $=1$-di(2-pyridyl)methyl4,7-dimethyl-1,4,7-triazacyclononane; tpen $=N, N, N^{\prime}, N^{\prime}$-tetrakis(2-pyridylmethyl)-1,2-diaminoethane; TPP = meso-tetraphenylporphyrin dianion; $\mathrm{Tp}^{3,5-\mathrm{iPr} 2}=$ hydrotris(3,5-diisopropylpyrazolyl)borate; trispicMeen $=$ $N$-methyl- $N, N^{\prime}, N^{\prime}$-tris(2-pyridylmethyl)-1,2-diaminoethane.

(14) Burger, R. M.; Kent, T. A.; Horwitz, S. B.; Münck, E.; Peisach, J. J. Biol. Chem. 1983, 258, 1559-1564.

(15) Sam, J. W.; Tang, X.-J.; Peisach, J. J. Am. Chem. Soc. 1994, 116, $5250-5256$.

(16) Loeb, K. E.; Zaleski, J. M.; Westre, T. E.; Guajardo, R. J.; Mascharak, P. K.; Hedman, B.; Hodgson, K. O.; Solomon, E. I. J. Am. Chem. Soc. 1995, 117, 4545-4561.

(17) Neese, F.; Zaleski, J. M.; Zaleski, K. L.; Solomon, E. I. J. Am. Chem. Soc. 2000, 122, 11703-11724.

(18) Guajardo, R. J.; Hudson, S. E.; Brown, S. J.; Mascharak, P. K. J. Am. Chem. Soc. 1993, 115, 7971-7977.

(19) Guajardo, R. J.; Chavez, F.; Farinas, E. T.; Mascharak, P. K. J. Am. Chem. Soc. 1995, 117, 3883-3884.
Scheme 1. Key Ligands and Complexes in This Study

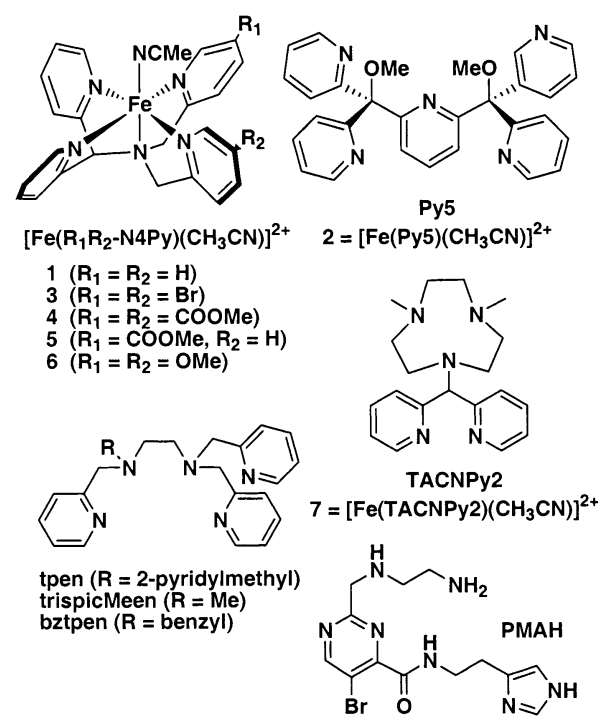

evidence for the $\mathrm{Fe}^{\mathrm{III}} \mathrm{OOH}$ formulation of the intermediate was reported. More recently, metastable $\mathrm{Fe}^{\mathrm{III}}-\mathrm{OOH}$ and $\mathrm{Fe}^{\mathrm{III}}$-OOR intermediates have been trapped at low temperature and characterized by a variety of spectroscopic methods; both low-spin and high-spin forms have been observed. ${ }^{20-22}$

A subset of these consists of low-spin $\mathrm{Fe}^{\mathrm{III}}-\mathrm{OOH}$ complexes derived from pentadentate N5 ligands such as N4Py, Py5, tpen, trispicMeen, and bztpen (Scheme 1), obtained from the treatment of iron(II) or iron(III) precursors with excess $\mathrm{H}_{2} \mathrm{O}_{2}$ at low temperature. ${ }^{23-32}$ These complexes exhibit EPR parameters similar to those of activated BLM, and their formulation as $[\mathrm{Fe}(\mathrm{L}) \mathrm{OOH}]^{2+}$ species has been established in several instances by the use of electrospray mass spectrometry. More importantly, the absence of other chromophores has allowed the peroxo-to-iron(III) chargetransfer transitions of these complexes to be identified in

(20) Girerd, J.-J.; Banse, F.; Simaan, A. J. Struct. Bonding 2000, 97, $143-$ 177.

(21) Wada, A.; Ogo, S.; Nagatomo, S.; Kitagawa, T.; Watanabe, Y.; Jitsukawa, K.; Masuda, H. Inorg. Chem. 2002, 41, 616-618.

(22) Shearer, J.; Scarrow, R. C.; Kovacs, J. A. J. Am. Chem. Soc. 2002, $124,11709-11717$.

(23) Lubben, M.; Meetsma, A.; Wilkinson, E. C.; Feringa, B.; Que, L., Jr. Angew. Chem., Int. Ed. Engl. 1995, 34, 1512-1514.

(24) Ho, R. Y. N.; Roelfes, G.; Feringa, B. L.; Que, L., Jr. J. Am. Chem. Soc. 1999, 121, 264-265.

(25) Roelfes, G.; Lubben, M.; Chen, K.; Ho, R. Y. N.; Meetsma, A.; Genseberger, S.; Hermant, R. M.; Hage, R.; Mandal, S. K.; Young, V. G., Jr.; Zang, Y.; Kooijman, H.; Spek, A. L.; Que, L., Jr.; Feringa, B. L. Inorg. Chem. 1999, 38, 1929-1936.

(26) de Vries, M. E.; La Crois, R. M.; Roelfes, G.; Kooijman, H.; Spek, A. L.; Hage, R.; Feringa, B. L. Chem. Commun. 1997, 1549-1550.

(27) Bernal, I.; Jensen, I. M.; Jensen, K. B.; McKenzie, C. J.; Toftlund, H.; Tuchagues, J. P. J. Chem. Soc., Dalton Trans. 1995, 3667-3675.

(28) Simaan, A. J.; Banse, F.; Mialane, P.; Boussac, A.; Un, S.; KargarGrisel, T.; Bouchoux, G.; Girerd, J.-J. Eur. J. Inorg. Chem. 1999, $993-$ 996.

(29) Jensen, K. B.; McKenzie, C. J.; Nielsen, L. P.; Pedersen, J. Z.; Svendsen, H. M. Chem. Commun. 1999, 1313-1314.

(30) Simaan, A. J.; Döpner, S.; Banse, F.; Bourcier, S.; Bouchoux, G.; Boussac, A.; Hildebrandt, P.; Girerd, J.-J. Eur. J. Inorg. Chem. 2000, $1627-1633$

(31) Simaan, A. J.; Banse, F.; Girerd, J.-J.; Wieghardt, K.; Bill, E. Inorg. Chem. 2001, 40, 6538-6540.

(32) Hazell, A.; McKenzie, C. J.; Nielsen, L. P.; Schindler, S.; Weitzer, M. J. Chem. Soc., Dalton Trans. 2002, 310-317. 
the visible region; probing the charge-transfer band by resonance Raman spectroscopy reveals that the low-spin $\mathrm{Fe}^{\mathrm{III}}-\mathrm{OOH}$ center has a weakened $\mathrm{O}-\mathrm{O}$ bond. ${ }^{20,24}$ These complexes provide experimental support for the notion derived from DFT calculations on both porphyrin and nonporphyrin complexes that the presence of a low-spin iron(III) center is an important factor for weakening the $\mathrm{O}-\mathrm{O}$ bond and promoting its cleavage. ${ }^{33-37}$

Treatment of these low-spin $\mathrm{Fe}-\mathrm{OOH}$ complexes with base converts them into new high-spin iron(III) species, ${ }^{20,29-32,38}$ and mixed isotope resonance Raman experiments strongly implicate a side-on bound peroxo ligand. ${ }^{38}$ The only other established ( $\eta^{2}$-peroxo)iron complexes prior to these studies are those of $\mathrm{Fe}^{\mathrm{III}}(\mathrm{EDTA}){ }^{39}$ and $\mathrm{Fe}^{\mathrm{III}}$ (porphyrin) ${ }^{40}$ The existence of an acid-base equilibrium affording low-spin $\mathrm{Fe}^{\mathrm{III}}$ $\eta^{1}-\mathrm{OOH}$ and high-spin $\mathrm{Fe}{ }^{\mathrm{III}}-\eta^{2}-\mathrm{O}_{2}$ species in one ligand system provides a unique opportunity to investigate how the change in peroxo binding mode affects the spectroscopic properties of the metal center.

In this paper, we report the synthesis and characterization of a family of iron(II) complexes with pentadentate N5 ligands, the generation of corresponding low-spin $\mathrm{Fe}^{\mathrm{III}}-\mathrm{OOH}$ intermediates, and how the various ligands affect the Raman properties of the $\mathrm{Fe}-\mathrm{OOH}$ unit. A detailed spectroscopic study of the parent $\left[(\mathrm{N} 4 \mathrm{Py}) \mathrm{Fe}^{\mathrm{III}}\left(\eta^{1}-\mathrm{OOH}\right)\right]^{2+}(\mathbf{1 a})$ ion in this series and its conjugate base $\left[(\mathrm{N} 4 \mathrm{Py}) \mathrm{Fe}^{\mathrm{III}}\left(\eta^{2}-\mathrm{O}_{2}\right)\right]^{+}(\mathbf{1 b})$ provides insights into their physical structure and electronic properties.

\section{Experimental Section}

Syntheses. Synthetic procedures for the various ligands used can be found in the Supporting Information. Synthetic procedures for $\left[\mathrm{Fe}(\mathrm{N} 4 \mathrm{Py})\left(\mathrm{CH}_{3} \mathrm{CN}\right)\right]\left(\mathrm{ClO}_{4}\right)_{2}(\mathbf{1})$ and $\left[\mathrm{Fe}(\mathrm{Py} 5)\left(\mathrm{CH}_{3} \mathrm{CN}\right)\right]\left(\mathrm{ClO}_{4}\right)_{2}(\mathbf{2})$ have been reported previously. ${ }^{25,26}$ All other iron(II) complexes were synthesized using the following procedure. To a solution of the appropriate N4Py ligand $(0.2-0.3 \mathrm{mmol})$ in methanol $(3 \mathrm{~mL})$ was added a solution of an equimolar amount of $\mathrm{Fe}\left(\mathrm{ClO}_{4}\right)_{2} \cdot 6 \mathrm{H}_{2} \mathrm{O}$ in $\mathrm{CH}_{3} \mathrm{CN}(3 \mathrm{~mL})$. The solution was placed in an ethyl acetate bath, and after 2 days the desired iron(II) complex was obtained as red microcrystals. CAUTION: Perchlorate salts of metal complexes with organic ligands are potentially explosive and should be handled with care!

[Fe(5-Br $\left.\left.\mathbf{- N}_{2}-\mathbf{P y}\right)\left(\mathrm{CH}_{3} \mathbf{C N}\right)\right]\left(\mathrm{ClO}_{4}\right)_{2} \mathbf{( 3 )}: 141 \mathrm{mg}, 0.19 \mathrm{mmol}$, $68 \%$ from $0.31 \mathrm{mmol}$ of ligand. ${ }^{1} \mathrm{H}$ NMR $\left(\mathrm{CD}_{3} \mathrm{CN}\right): \delta 4.32\left(\mathrm{q}_{(\mathrm{AB})}\right)$, $4 \mathrm{H}, J=18.3 \mathrm{~Hz}), 6.29(\mathrm{~s}, 1 \mathrm{H}), 6.95(\mathrm{~d}, 2 \mathrm{H}, J=8.4 \mathrm{~Hz}), 7.33(\mathrm{~m}$, $2 \mathrm{H}), 7.85(\mathrm{~d}, 2 \mathrm{H}, J=8.4 \mathrm{~Hz}), 7.92(\mathrm{t}, 2 \mathrm{H}, J=7.7 \mathrm{~Hz}), 8.87(\mathrm{~d}$, $2 \mathrm{H}, J=5.1 \mathrm{~Hz}), 9.11(\mathrm{~d}, 2 \mathrm{H}, J=2.2 \mathrm{~Hz})$. Anal. Calcd for $\mathrm{C}_{25} \mathrm{H}_{22}-$ $\mathrm{Br}_{2} \mathrm{Cl}_{2} \mathrm{FeN}_{6} \mathrm{O}_{8}: \mathrm{C}, 36.57 ; \mathrm{H}, 2.70 ; \mathrm{N}, 10.24$. Found: $\mathrm{C}, 36.20 ; \mathrm{H}$, 2.87; N, 10.27 .

(33) Harris, D. L.; Loew, G. H. J. Am. Chem. Soc. 1998, 120, 8941-8948.

(34) Loew, G. H.; Harris, D. L. Chem. Rev. 2000, 100, 407-419.

(35) Lehnert, N.; Ho, R. Y. N.; Que, L., Jr.; Solomon, E. I. J. Am. Chem. Soc. 2001, 123, 8271-8290.

(36) Lehnert, N.; Ho, R. Y. N.; Que, L., Jr.; Solomon, E. I. J. Am. Chem. Soc. 2001, 123, 12802-12816.

(37) Lehnert, N.; Neese, F.; Ho, R. Y. N.; Que, L., Jr.; Solomon, E. I. J. Am. Chem. Soc. 2002, 124, 10810-10822.

(38) Ho, R. Y. N.; Roelfes, G.; Hermant, R.; Hage, R.; Feringa, B. L.; Que, L., Jr. Chem. Commun. 1999, 2161-2162.

(39) Neese, F.; Solomon, E. I. J. Am. Chem. Soc. 1998, 120, 12829-12848.

(40) Burstyn, J. N.; Roe, J. A.; Miksztal, A. R.; Shaevitz, B. A.; Lang, G.; Valentine, J. S. J. Am. Chem. Soc. 1988, 110, 1382-1388.
$\left[\mathrm{Fe}\left(\mathbf{5}-(\mathrm{MeOOC})_{2}-\mathbf{N} 4 \mathrm{Py}\right)\left(\mathrm{CH}_{3} \mathrm{CN}\right)\right]\left(\mathrm{ClO}_{4}\right)_{2} \quad$ (4): $96 \mathrm{mg}, 0.12$ mmol, $82 \%$ yield from $0.15 \mathrm{mmol}$ ligand. ${ }^{1} \mathrm{H}$ NMR $\left(\mathrm{CD}_{3} \mathrm{CN}\right): \delta$ $3.94(\mathrm{~s}, 6 \mathrm{H}), 4.45\left(\mathrm{q}_{(\mathrm{AB})}, 4 \mathrm{H}, J=18.7 \mathrm{~Hz}\right), 6.40(\mathrm{~s}, 1 \mathrm{H}), 7.21(\mathrm{~d}$, $2 \mathrm{H}, J=8.1 \mathrm{~Hz}),(\mathrm{t}, 2 \mathrm{H}, J=6.2 \mathrm{~Hz}), 7.91(\mathrm{~m}, 4 \mathrm{H}), 8.14(\mathrm{~d}, 2 \mathrm{H}$, $J=8.1 \mathrm{~Hz}), 8.91(\mathrm{~d}, 2 \mathrm{H}, J=4.8 \mathrm{~Hz}), 9.48(\mathrm{~s}, 2 \mathrm{H})$. Anal. Calcd for $\mathrm{C}_{29} \mathrm{H}_{28} \mathrm{Cl}_{2} \mathrm{FeN}_{6} \mathrm{O}_{12}$ : C, 44.69; H, 3.62; N, 10.78. Found: C, 44.28; H, 3.69; N, 10.63.

[Fe(5-(MeOOC)-N4Py)(CH3 $\mathbf{C N})]\left(\mathrm{ClO}_{4}\right)_{2} \quad$ (5): $80 \mathrm{mg}, 0.11$ mmol, $93 \%$ yield from $0.13 \mathrm{mmol}$ ligand. ${ }^{1} \mathrm{H} \mathrm{NMR}\left(\mathrm{CD}_{3} \mathrm{CN}\right): \delta$ $3.91(\mathrm{~s}, 3 \mathrm{H}), 4.36(\mathrm{~m}, 4 \mathrm{H}), 6.34(\mathrm{~s}, 1 \mathrm{H}), 7.07(\mathrm{~d}, 1 \mathrm{H}, J=8.1 \mathrm{~Hz})$, $7.16(\mathrm{~d}, 1 \mathrm{H}, J=8.1 \mathrm{~Hz}), 7.32(\mathrm{~m}, 3 \mathrm{H}), 7.67(\mathrm{dt}, 1 \mathrm{H}, J=8.1 \mathrm{~Hz}$, $J=1.5 \mathrm{~Hz}), 7.87(\mathrm{~m}, 4 \mathrm{H}), 8.11(\mathrm{dd}, 1 \mathrm{H}, J=8.1 \mathrm{~Hz}, J=1.5 \mathrm{~Hz})$, $8.87(\mathrm{~d}, 1 \mathrm{H}, 5.1 \mathrm{~Hz}), 8.90(\mathrm{~d}, 1 \mathrm{H}, J=5.1 \mathrm{~Hz}), 9.08(\mathrm{~d}, 1 \mathrm{H}, J=$ $4.8 \mathrm{~Hz}), 9.42\left(\mathrm{~d}, 1 \mathrm{H}, J=1.1 \mathrm{~Hz}\right.$ ). Anal. Calcd for $\mathrm{C}_{27} \mathrm{H}_{26} \mathrm{Cl}_{2-}$ $\mathrm{FeN}_{6} \mathrm{O}_{10}$ : C, 47.82; $\mathrm{H}, 4.01 ; \mathrm{N}, 11.95$. Found: $\mathrm{C}, 47.50 ; \mathrm{H}, 4.02$; $\mathrm{N}, 11.70$.

[Fe(5-(MeO) $\left.\left.)_{2}-\mathbf{N} 4 \mathrm{Py}\right)\left(\mathrm{CH}_{3} \mathrm{CN}\right)\right]\left(\mathrm{ClO}_{4}\right)_{2}$ (6): $83 \mathrm{mg}, 0.12 \mathrm{mmol}$, $57 \%$ yield from $0.21 \mathrm{mmol}$ ligand. ${ }^{1} \mathrm{H} \mathrm{NMR}\left(\mathrm{CD}_{3} \mathrm{CN}\right): \delta 3.87(\mathrm{~s}$, $6 \mathrm{H}), 4.22\left(\mathrm{q}_{(\mathrm{AB})}, 4 \mathrm{H}, J=17.9 \mathrm{~Hz}\right), 6.25(\mathrm{~s}, 1 \mathrm{H}), 6.98(\mathrm{~d}, 2 \mathrm{H}, J=$ $8.8 \mathrm{~Hz}), 7.25(\mathrm{dd}, 2 \mathrm{H}, J=8.8 \mathrm{~Hz}, J=2.9 \mathrm{~Hz}), 7.34(\mathrm{~m}, 2 \mathrm{H}), 7.86$ $(\mathrm{m}, 2 \mathrm{H}), 8.68(\mathrm{~d}, 2 \mathrm{H}, J=2.6 \mathrm{~Hz}), 8.92(\mathrm{~d}, 2 \mathrm{H}, J=5.1 \mathrm{~Hz})$. Anal. Calcd for $\mathrm{C}_{27} \mathrm{H}_{28} \mathrm{Cl}_{2} \mathrm{FeN}_{6} \mathrm{O}_{10}$ : C, 44.84; $\mathrm{H}, 3.90 ; \mathrm{N}, 11.62$. Found: C, 44.92; H, 4.03; N, 11.57.

[(Fe(TACNPy2)(CH $\left.\left.\mathbf{C H}_{3} \mathbf{C N}\right)\right]\left(\mathbf{C l O}_{4}\right)_{2}$ (7): $90 \mathrm{mg}, 0.14 \mathrm{mmol}, 43 \%$ yield from $0.33 \mathrm{mmol}$ ligand. ${ }^{1} \mathrm{H} \mathrm{NMR}\left(\mathrm{CD}_{3} \mathrm{CN}\right): \delta 2.73(\mathrm{~s}, 6 \mathrm{H})$, $2.86(\mathrm{~m}, 6 \mathrm{H}), 2.96(\mathrm{~m}, 6 \mathrm{H}), 6.09(\mathrm{~s}, 1 \mathrm{H}), 7.33(\mathrm{~m}, 2 \mathrm{H}), 7.79(\mathrm{~d}$, $2 \mathrm{H}, J=7.7 \mathrm{~Hz}), 7.88(\mathrm{dt}, 2 \mathrm{H}, J=7.7 \mathrm{~Hz}, J=1.1 \mathrm{~Hz}), 8.99(\mathrm{~d}$, $2 \mathrm{H}, J=5.5 \mathrm{~Hz}$ ). Anal. Calcd for $\mathrm{C}_{21} \mathrm{H}_{30} \mathrm{Cl}_{2} \mathrm{FeN}_{6} \mathrm{O}_{8}: \mathrm{C}, 40.60 ; \mathrm{H}$, 4.87; N, 13.53. Found: C, 40.56; H, 4.85; N, 13.43.

$\left[{ }^{54} \mathbf{F e}(\mathbf{N} 4 \mathrm{Py})\left(\mathrm{CH}_{3} \mathrm{CN}\right)\right]\left(\mathrm{ClO}_{4}\right)_{2}$. A piece of ${ }^{54} \mathrm{Fe}$ metal $(8.2 \mathrm{mg}$, $0.15 \mathrm{mmol}$ ) broken into smaller particles was added to $70 \%$ perchloric acid $(47 \mathrm{mg}, 0.33 \mathrm{mmol}$ ) in a micro test tube (no magnetic stirring bar!). The mixture was carefully heated using a heat gun, during which time an orange color appeared. An additional aliquot of $70 \% \mathrm{HClO}_{4}(18 \mathrm{mg}, 0.13 \mathrm{mmol})$ was added, and the mixture was heated for 30 min. During the reaction $\mathrm{H}_{2} \mathrm{O}(4 \times 20$ $\mu \mathrm{L}$ ) was added to compensate for evaporation. After standing at room temperature for $1.5 \mathrm{~h}$ all iron had disappeared and $\mathrm{MeOH}$ (1 $\mathrm{mL})$ was added. A solution of N4Py $(60 \mathrm{mg}, 0.17 \mathrm{mmol})$ in $\mathrm{CH}_{3^{-}}$ $\mathrm{CN}$ (1 mL) was added, and the resulting dark red solution was placed in an ethyl acetate bath. After standing overnight red crystals formed, which were isolated and washed with ethyl acetate. The crystals were redissolved in $\mathrm{CH}_{3} \mathrm{CN}$ and placed in an ethyl acetate bath to afford $\left.{ }^{54} \mathrm{Fe}(\mathrm{N} 4 \mathrm{Py})\left(\mathrm{CH}_{3} \mathrm{CN}\right)\right]\left(\mathrm{ClO}_{4}\right)_{2}(86 \mathrm{mg}, 0.13 \mathrm{mmol}$, $87 \%)$ as red crystals after 3 days. ${ }^{1} \mathrm{H}$ NMR $\left(\mathrm{CD}_{3} \mathrm{CN}\right): \delta 4.34\left(\mathrm{q}_{(\mathrm{AB})}\right.$, $4 \mathrm{H}, J=18.3 \mathrm{~Hz}), 6.34(\mathrm{~s}, 1 \mathrm{H}), 7.06(\mathrm{~d}, 2 \mathrm{H}, J=7.9 \mathrm{~Hz}), 7.35(\mathrm{~m}$, $4 \mathrm{H}), 7.68(\mathrm{~m}, 2 \mathrm{H}), 7.91(\mathrm{~m}, 4 \mathrm{H}), 8.91(\mathrm{~d}, 2 \mathrm{H}, J=5.3 \mathrm{~Hz}), 9.04$ $(\mathrm{d}, 2 \mathrm{H}, J=5.6 \mathrm{~Hz})$; ES/MS: $m / z, 520\left[\mathrm{M}-\mathrm{ClO}_{4}-\mathrm{CH}_{3} \mathrm{CN}\right]^{+}$, $210.5\left[\mathrm{M}-2 \mathrm{ClO}_{4}-\mathrm{CH}_{3} \mathrm{CN}\right]^{2+}$. The ${ }^{57} \mathrm{Fe}$ isotopomer was prepared in a similar fashion.

Physical Methods. ${ }^{1} \mathrm{H}$ NMR and ${ }^{13} \mathrm{C}$ NMR spectra were recorded on a Varian Gemini 300 spectrometer at ambient temperature $\left({ }^{1} \mathrm{H}\right.$ at $300 \mathrm{MHz}$ and ${ }^{13} \mathrm{C}$ at $75 \mathrm{MHz}$ ). Chemical shifts (in $\mathrm{ppm}$ ) were referenced to the residual solvent peaks. Visible spectra were recorded on a Hewlett-Packard 8453 diode array spectrophotometer. Electrochemical studies were carried out with a PAR 273A potentiostat in acetonitrile using $0.1 \mathrm{M}$ tetrabutylammonium perchlorate as the supporting electrolyte. Cyclic voltammograms (CV) were obtained by using a three-component system consisting of a glassy carbon working electrode, a platinum wire auxiliary electrode, and a saturated calomel reference electrode. Resonance Raman spectra were collected on an Acton AM-506 spectrometer (2400-groove grating) using Kaiser Optical holographic super-notch 
filters with a Princeton Instruments liquid $\mathrm{N}_{2}$ cooled (LN-1100PB) CCD detector with $4-$ or $2-\mathrm{cm}^{-1}$ spectral resolution. Spectra were obtained by backscattering geometry on liquid $\mathrm{N}_{2}$ frozen samples using $568.2 \mathrm{~nm}$ laser excitation from a Spectra Physics 2030-15 argon ion laser and a 375B CW dye (Rhodamine 6G). Raman frequencies were referenced to indene.

Mössbauer spectra were recorded with two spectrometers, using Janis Research Super-Varitemp dewars that allowed studies in applied magnetic fields up to $8.0 \mathrm{~T}$ in the temperature range from 1.5 to $200 \mathrm{~K}$. Mössbauer spectral simulations were performed using the WMOSS software package (WEB Research, Edina, MN). Isomer shifts are quoted relative to Fe metal at $298 \mathrm{~K}$. EPR spectra were recorded on a Bruker EPP 300 spectrometer equipped with an Oxford ESR 910 liquid helium cryostat and an Oxford temperature controller.

X-ray absorption spectroscopy (XAS) data were collected at beamline X9 of the National Synchrotron Light Source at Brookhaven National Laboratory. X-ray absorption spectra at the iron K-edge were collected between 6.9 and $8.0 \mathrm{keV}$ as described previously, ${ }^{41,42}$ and the monochromator was calibrated using the edge energy of iron foil at $7112.0 \mathrm{eV}$. The data were obtained in transmission mode $\left(A_{\exp }=-\log I_{\mathrm{t}} / I_{0}\right)$ or fluorescence mode $\left(A_{\exp }\left(C_{\mathrm{f}} / C_{0}\right)\right)$ at $10-20$ $\mathrm{K}$.

The treatment of raw EXAFS data to yield $\chi$ is discussed in detail in review articles. ${ }^{43,44} \mathrm{~A}$ modification of the EXAPLT program was employed to extract $\chi$ from $A_{\text {exp }}$ by using a cubic spline function, including preliminary baseline correction and correction of fluorescence data for thickness effects and detector response. ${ }^{41}$ The refinements reported were on $k^{3} \chi$ data, and the function minimized was $R=\left\{\sum k^{6}\left(\chi_{\mathrm{c}}-\chi\right)^{2} / N\right\}^{1 / 2}$, where the sum is over $N$ data points within the selected $k$ space. The fitting results indicate the average metal-ligand distances, the type and the number of scatterers, and the Debye-Waller factors which can be used to evaluate the distribution of $\mathrm{Fe}$-ligand bond lengths in each shell. The EXAFS goodness of fit criterion applied here is

$$
\epsilon^{2}=\left[\left(N_{\mathrm{idp}} / v\right) \sum\left(\chi_{\mathrm{c}}-\chi\right)^{2} / \sigma^{2}\right] / N
$$

as recommended by the International Committee on Standards and Criteria in $\mathrm{EXAFS}^{45}$ where $v$ is the number of degrees of freedom calculated as $v=N_{\text {idp }}-N_{\text {var }}, N_{\text {idp }}$ is the number of independent data points, and $N_{\mathrm{var}}$ is the number of variables that are refined. $N_{\text {idp }}$ is calculated as $N_{\text {idp }}=2 \Delta k \Delta R / \pi+2 .{ }^{46}$ The use of $\epsilon^{2}$ as the criterion for the goodness of fit allows us to compare fits using different numbers of variable parameters.

Crystallographic Studies. A red block-shaped crystal of $\mathbf{7}$ was measured on an Enraf-Nonius CAD4T diffractometer with rotating anode $(\lambda=0.71073 \AA)$ at a temperature of $150(2) \mathrm{K}$ up to a resolution of $\sin \theta / \lambda=0.595 \AA^{-1}$. The structure was solved with direct methods $\left(\right.$ SIR97 ${ }^{47}$ ) and refined with SHELXL97 ${ }^{48}$ against $F^{2}$ of all reflections using 370 refined parameters. Non-hydrogen atoms were refined freely with anisotropic displacement parameters. Hydrogen atoms were refined as rigid groups. The perchlorate ions

(41) Scarrow, R. C.; Maroney, M. J.; Palmer, S. M.; Roe, A. L.; Que, L., Jr.; Salowe, S. P.; Stubbe, J. J. Am. Chem. Soc. 1987, 109, 78577864.

(42) Shu, L.; Chiou, Y.-M.; Orville, A. M.; Miller, M. A.; Lipscomb, J. D.; Que, L., Jr. Biochemistry 1995, 34, 6649-6659.

(43) Scott, R. A. Methods Enzymol. 1985, 11, 414-459.

(44) Teo, B.-K. EXAFS Spectroscopy, Techniques and Applications; Plenum: New York, 1981.

(45) Riggs-Gelasco, P. J.; Stemmler, T. L.; Penner-Hahn, J. E. Coord. Chem. Rev. 1995, 144, 245-286.

(46) Stern, E. Phys. Rev. 1993, B48, 9825-9827. were refined with disorder models (rotational disorder). Checking for higher symmetry and structure calculations were performed with the PLATON $^{49}$ package.

Computational Details. Density functional calculations were performed using Becke's three-parameter hybrid functional (B3LYP) provided by the Gaussian 98 (releases A.9 and A.11) software package. ${ }^{50}$ The SCF calculations were terminated upon reaching tight convergence criteria $\left(10^{-6} \mathrm{rmsd}\right.$ in the density matrix and $10^{-8}$ au maximum deviation in energy), and default criteria for geometry optimization (maximum force $-4.5 \times 10^{-4}$ au and $\mathrm{rms} 3.0 \times 10^{-4}$ $\mathrm{au}$, and maximum displacement $-1.8 \times 10^{-3}$ au and $\mathrm{rms} 1.2 \times$ $10^{-3} \mathrm{au}$ ). Initial geometries for the low-spin hydroperoxo (1a) and high-spin peroxo (1b) complexes were obtained from the structure of $1 \mathbf{c},,^{25}$ and the methoxy group was replaced by end-on bound monoanionic hydroperoxo and dianionic peroxo ligands, respectively. The structures of the complexes were optimized using the Berny optimization procedure and the LanL2DZ double- $\zeta$ pseudopotential basis. The resultant optimized geometries and electronic structures were used as the starting point for an all-electron basis set geometry optimization by including the Pople 6-311G basis set for light atoms and the Wachters $(+\mathrm{f})$ basis set for the iron center. ${ }^{51}$ Addition of polarization functions of light atoms did not significantly improve the calculated $\mathrm{Fe}-\mathrm{L}$ bond distances. The quadrupole splittings were calculated from the electric field gradients using $Q=0.16$ barn. In order to assess the valence contribution to the field gradient of $\mathbf{1 a}, \mathrm{Fe}^{3+}$ was replaced with $\mathrm{Ga}^{3+}$ in the optimized structure of the hydroperoxo complex and the calculations were performed using the $6-311 \mathrm{G}$ basis set for all atoms. The spin-dipolar contributions to the A-tensor were computed by the method of Barone et al. ${ }^{52}$ as implemented in the Gaussian 98 package.

\section{Results and Discussion}

A Family of Iron(II) Complexes with Pentadentate N5 Ligands. Iron(II) complexes of the pentadentate N5 ligands shown in Scheme 1 were obtained by reaction of the ligand with $\mathrm{Fe}\left(\mathrm{ClO}_{4}\right)_{2} \cdot 6 \mathrm{H}_{2} \mathrm{O}$ in methanol/ $\mathrm{CH}_{3} \mathrm{CN}$ or pure $\mathrm{CH}_{3} \mathrm{CN}$. Slow vapor diffusion of ethyl acetate into these solutions afforded the iron complexes as red crystalline material. These complexes gave elemental analyses consistent with their formulation as $\left[(\mathrm{L}) \mathrm{Fe}\left(\mathrm{CH}_{3} \mathrm{CN}\right)\right]\left(\mathrm{ClO}_{4}\right)_{2}(\mathbf{1}-\mathbf{7}$, see Scheme 1 for ligand structures). Furthermore, all complexes exhibit NMR spectra with sharp features in the $0-10 \mathrm{ppm}$ region.

(47) Altomare, A.; Burla, M. C.; Camalli, M.; Cascarano, G. L.; Giacovazzo, C.; Guagliardi, A.; Moliterni, A. G. G.; Polidori, G.; Spagna, R. J. Appl. Crystallogr. 1999, 32, 115-119.

(48) Sheldrick, G. M. SHELXL-97, Program for crystal structure refinement; University of Göttingen: Göttingen, Germany, 1997.

(49) Spek, A. L. PLATON. A multipurpose crystallographic tool; Utrecht University, The Netherlands, 2002.

(50) Frisch, M. J.; Trucks, G. W.; Schlegel, H. B.; Scuseria, G. E.; Robb, M. A.; Cheeseman, J. R.; Zakrzewski, V. G.; Montgomery, J. A., Jr.; Stratmann, R. E.; Burant, J. C.; Dapprich, S.; Millam, J. M.; Daniels, A. D.; Kudin, K. N.; Strain, M. C.; Farkas, O.; Tomasi, J.; Barone, V.; Cossi, M.; Cammi, R.; Mennucci, B.; Pomelli, C.; Adamo, C.; Clifford, S.; Ochterski, J.; Petersson, G. A.; Ayala, P. Y.; Cui, Q.; Morokuma, K.; Malick, D. K.; Rabuck, A. D.; Raghavachari, K.; Foresman, J. B.; Cioslowski, J.; Ortiz, J. V.; Stefanov, B. B.; Liu, G.; Liashenko, A.; Piskorz, P.; Komaromi, I.; Gomperts, R.; Martin, R. L.; Fox, D. J.; Keith, T.; Al-Laham, M. A.; Peng, C. Y.; Nanayakkara, A.; Gonzalez, C.; Challacombe, M.; Gill, P. M. W.; Johnson, B. G.; Chen, W.; Wong, M. W.; Andres, J. L.; Head-Gordon, M.; Replogle, E. S.; Pople, J. A. Gaussian 98, releases A.9 and A.11; Gaussian Inc.: Pittsburgh, PA, 1998.

(51) Wachters, A. J. H. J. Chem. Phys. 1970, 52, 1033-1036.

(52) Rega, N.; Cossi, M.; Barone, V. J. Chem. Phys. 1996, 105, 11060. 


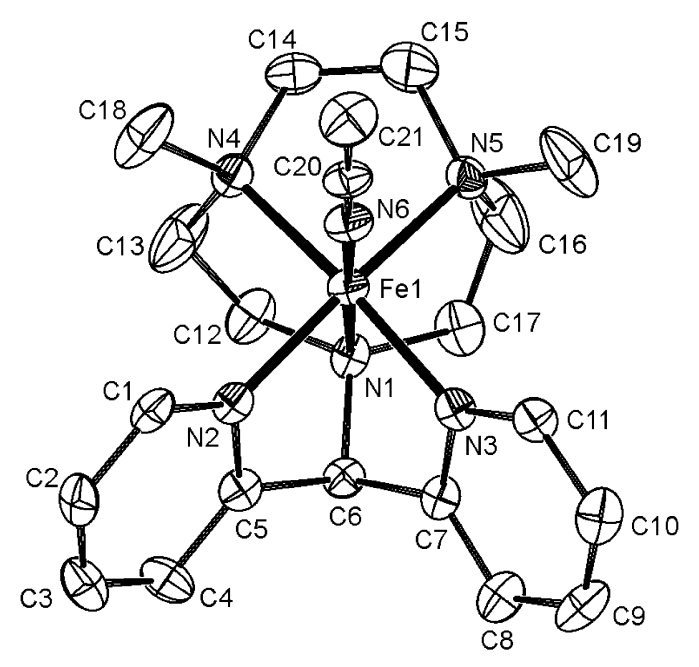

Figure 1. ORTEP plot of the cation of 7 showing $50 \%$ probability ellipsoids, with hydrogen atoms omitted for clarity. Selected distances

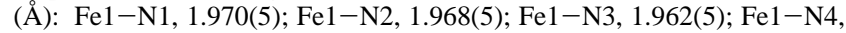
2.047(5); $\mathrm{Fe} 1-\mathrm{N} 5,2.043(5)$; Fe1-N6, 1.921(5); Fe-(mean equatorial plane), 0.183(1)

Thus, as previously reported for $\left[\mathrm{Fe}(\mathrm{N} 4 \mathrm{Py})\left(\mathrm{CH}_{3} \mathrm{CN}\right)\right]\left(\mathrm{ClO}_{4}\right)_{2}$ (1), ${ }^{25}$ all complexes have low-spin iron(II) centers.

The crystal structure of $\mathbf{7}$ was solved to reveal a cation with an approximate, noncrystallographic mirror symmetry (Figure 1). It consists of a six-coordinate $\mathrm{Fe}^{\mathrm{II}}$ center with five coordination sites occupied by the $\mathrm{N}$ atoms of the ligand, and the sixth coordination site occupied by an acetonitrile molecule. The $\mathrm{Fe}-\mathrm{N}_{\mathrm{py}}$ bonds of 1.968(5) and 1.962(5) $\AA$ and the $\mathrm{Fe}-\mathrm{N}_{\text {amine }}$ bond to the apical nitrogen of 1.970(5) $\AA$ are comparable in length to all five of the $\mathrm{Fe}-\mathrm{N}_{\text {ligand }}$ bonds of $\mathbf{1}$, which are typical of low-spin $\mathrm{Fe}^{\mathrm{II}}$ complexes. However, the other two $\mathrm{Fe}-\mathrm{N}_{\text {amine }}$ bonds (2.047(5) and 2.043(5) $\AA$ ) are longer than expected, possibly due to steric interactions introduced by the $\mathrm{N}$-methyl groups. The iron atom in $\mathbf{7}$ lies 0.183(1) A above the plane formed by N2, N3, N4, and N5, comparable to the out-of-plane displacement observed for 1.

Cyclic voltammetry of the iron(II) complexes in $\mathrm{CH}_{3} \mathrm{CN}$ showed a single quasi-reversible wave near $1 \mathrm{~V}$ vs SCE, ascribed to the $\mathrm{Fe}^{\mathrm{III}} / \mathrm{Fe}^{\mathrm{II}}$ couple (Table 1). From the data it is clear that the number of pyridine moieties on the ligand substituents exerts a major effect in determining the redox potential of the complex; the pentapyridine ligand Py5 affords the complex with the highest potential (1210 mV vs SCE), while the TACN ligand with only two pendant pyridines forms a complex with significantly lower potential $(902 \mathrm{mV}$ vs SCE). The various Fe(N4Py) complexes exhibit potentials between these two extremes, and substituents on the 5 position of the picolyl groups modulate the potentials, albeit only to a minor extent.

A Series of Low-Spin $\mathrm{Fe}^{\mathrm{III}}-\mathrm{OOH}$ Intermediates. Complexes 1-7 all react with excess $\mathrm{H}_{2} \mathrm{O}_{2}$ to form metastable purple or dark blue species (1a-7a, Table 1$)$, which can be trapped at lower temperature. As previously demonstrated, ${ }^{23-25}$ the formation of 1a occurs in two steps.

$$
\left[\mathrm{Fe}^{\mathrm{II}}(\mathrm{L})\left(\mathrm{CH}_{3} \mathrm{CN}\right)\right]^{2+} \rightarrow\left[\mathrm{Fe}^{\mathrm{III}}(\mathrm{L}) \mathrm{OH}\right]^{2+} \rightarrow\left[\mathrm{Fe}^{\mathrm{III}}(\mathrm{L}) \mathrm{OOH}\right]^{2+}
$$

In the first step 0.5 equiv of $\mathrm{H}_{2} \mathrm{O}_{2}$ converts the $\mathrm{Fe}^{\mathrm{II}}$ complex to an $\mathrm{Fe}^{\mathrm{III}}-\mathrm{OH}$ complex; in the second step excess $\mathrm{H}_{2} \mathrm{O}_{2}$ displaces the hydroxide to form the hydroperoxide complex. Intermediate 1a has a chromophore with $\lambda_{\max }$ at $548 \mathrm{~nm}$ (in $\mathrm{CH}_{3} \mathrm{OH}$ solvent, Figure 2) that has been shown to arise from a hydroperoxo-to-iron(III) charge-transfer transition of a lowspin $\mathrm{Fe}^{\mathrm{III}}-\mathrm{OOH}$ complex. ${ }^{24}$ The $\mathrm{Fe}^{\mathrm{III}}-\mathrm{OOH}$ intermediates could be generated in methanol or acetone solvent, except for 7a, which could only be obtained with the latter solvent. In general, the $\lambda_{\max }$ of the intermediate is lower in acetone than in methanol; for example, 1a exhibits a $\lambda_{\max }$ of $530 \mathrm{~nm}$ in acetone and $548 \mathrm{~nm}$ in methanol. The absorption band at 520-600 nm for N4Py-derived intermediates, i.e., 1a and $3 \mathbf{a}-6 \mathbf{a}$, has an $\epsilon$ value of $1000-1300 \mathrm{M}^{-1} \mathrm{~cm}^{-1}$, as found for other $\mathrm{Fe}^{\mathrm{III}}-\mathrm{OOH}$ complexes, but preparations of $\mathbf{2 a}$ and 7a have intensities approximately $30-50 \%$ of that of $\mathbf{1 a}$, probably due to incomplete formation of these intermediates. Figure 3A shows a linear correlation between the energy of the charge-transfer band in acetone solvent and the redox potential of the $\mathrm{Fe}^{\mathrm{III}} / \mathrm{Fe}^{\mathrm{II}}$ couple associated with the parent iron(II) complex. This result is not unexpected, as the energy of the hydroperoxide orbital involved in the LMCT band would be expected to remain constant in the series, while the energy of the destination metal $\mathrm{d}$ orbital would be expected to be sensitive to the same factors as the redox potential.

The EPR spectra of the $\mathrm{Fe}^{\mathrm{III}}-\mathrm{OOH}$ intermediates exhibit rhombic signals characteristic of low-spin iron(III) with $g$ $\sim 2.17,2.12$, and 1.98 , values which resemble those of activated bleomycin $(g=2.26,2.17,1.94) .{ }^{55}$ For $\mathbf{2 a}$ in methanol solvent, an additional set of signals was found at $g=2.27,2.13$, and 1.96, reminiscent of values observed for $\left[(\mathrm{N} 4 \mathrm{Py}) \mathrm{Fe}^{\mathrm{III}} \mathrm{OMe}\right]^{2+}(2.29,2.12,1.96) .{ }^{25}$ For $7 \mathbf{a}$ in acetone solvent, another set of signals was observed at $g=2.45$, 2.14, and 1.93, similar to those of $\left[(\mathrm{N} 4 \mathrm{Py}) \mathrm{Fe}^{\mathrm{III}} \mathrm{OH}\right]^{2+}(2.41$, $2.15,1.92)^{25}$ and $(\mathrm{BLM}) \mathrm{Fe}^{\mathrm{III}} \mathrm{OH}(2.45,2.18,1.89),{ }^{14}$ suggesting that residual $\left[(\mathrm{Py} 5) \mathrm{Fe}^{\mathrm{III}} \mathrm{OMe}\right]^{2+}$ and $\left[\left(\mathrm{TACNPy}_{2}\right) \mathrm{Fe}^{\mathrm{III}}-\right.$ $\mathrm{OH}]^{2+}$ were respectively present in the solutions of $\mathbf{2 a}$ and 7a. Since both $\mathrm{Fe}^{\mathrm{III}} \mathrm{OH}$ and $\mathrm{Fe}^{\mathrm{III}} \mathrm{OMe}$ complexes can serve as precursors for the $\mathrm{Fe}^{\mathrm{III}} \mathrm{OOH}$ intermediates, the presence of these signals suggests incomplete formation of the $\mathrm{Fe}^{\mathrm{III}}-$ $\mathrm{OOH}$ species, in agreement with the lower intensities found for the UV/vis spectra of $\mathbf{2 a}$ and $\mathbf{7 a}$.

Resonance Raman spectroscopy shows that these transient species do indeed have a bound hydroperoxide moiety, with resonance-enhanced features near 630 and $800 \mathrm{~cm}^{-1}$, as exemplified by the spectrum of $[\mathrm{Fe}(\mathrm{N} 4 \mathrm{Py}) \mathrm{OOH}]^{2+}$ (Figure $4 \mathrm{~A}$ ) and found for other low-spin iron(III) hydroperoxide complexes (Table 1). These features have been assigned to a $v\left(\mathrm{Fe}-\mathrm{O}_{2} \mathrm{H}\right)$ and a $v(\mathrm{O}-\mathrm{O})$ vibration, respectively, and are considered to be the Raman signature of a low-spin $\mathrm{Fe}^{\mathrm{III}}-$ $\mathrm{OOH}$ intermediate. ${ }^{20,24} \mathrm{In}$ contrast, almost all high-spin mono- and diiron(III) - peroxo complexes typically exhibit

(53) Ahmad, S.; McCallum, J. D.; Shiemke, A. K.; Appelman, E. H.; Loehr, T. M.; Sanders-Loehr, J. Inorg. Chem. 1988, 27, 2230-2233.

(54) Brunold, T. C.; Solomon, E. I. J. Am. Chem. Soc. 1999, 121, 82778287.

(55) Burger, R. M.; Peisach, J.; Horwitz, S. B. J. Biol. Chem. 1981, 256, $11636-11644$. 
Roelfes et al.

Table 1. Physical Properties of Iron(II) Precursor and Corresponding Iron(III)-Peroxo Complexes

\begin{tabular}{|c|c|c|c|c|c|}
\hline \multirow[b]{2}{*}{ ligand (complex) } & \multirow{2}{*}{$\begin{array}{c}{\left[(\mathrm{L}) \mathrm{Fe}^{\mathrm{II}}\left(\mathrm{CH}_{3} \mathrm{CN}\right)\right]^{2+}} \\
E_{1 / 2},{ }^{a} \\
\mathrm{mV} \text { vs } \mathrm{SCE}\end{array}$} & \multicolumn{3}{|c|}{$\left[(\mathrm{L}) \mathrm{Fe}^{\mathrm{III}} \mathrm{OO}(\mathrm{H})\right]$ complex } & \multirow[b]{2}{*}{ ref } \\
\hline & & $\begin{array}{c}\lambda_{\max }{ }^{b} \\
\operatorname{nm}\left(\epsilon_{\mathrm{M}}\right)\end{array}$ & $\begin{array}{c}\nu(\mathrm{Fe}-\mathrm{O}), \\
\mathrm{cm}^{-1}\left(\Delta^{18} \mathrm{O}\right)\end{array}$ & $\begin{array}{c}v(\mathrm{O}-\mathrm{O}), \\
\mathrm{cm}^{-1}\left(\Delta^{18} \mathrm{O}\right)\end{array}$ & \\
\hline \multicolumn{6}{|c|}{ Low-Spin $\mathrm{Fe}^{\mathrm{III}}-\mathrm{OOH}$ Complexes } \\
\hline Py5 (2) & 1210 & $592(c)$ & 627 & 806 & $d$ \\
\hline $5-\mathrm{Br}_{2}-\mathrm{N} 4 \mathrm{Py}(\mathbf{3})$ & 1100 & $557(1210)$ & 641 & 795 & $d$ \\
\hline $5-(\mathrm{COOMe})_{2}-\mathrm{N} 4 \mathrm{Py}(4)$ & 1096 & $559(1260)$ & 643 & 793 & $d$ \\
\hline 5-(COOMe)-N4Py (5) & 1046 & $553(1310)$ & & & $d$ \\
\hline N4Py (1) & 1010 & $548(1300)$ & $632(-16)$ & $790(-44)$ & $d$ \\
\hline $5-(\mathrm{MeO})_{2}-\mathrm{N} 4 \mathrm{Py}(6)$ & 996 & $549(1030)$ & 644 & 791 & $d$ \\
\hline TACNPy2 (7) & 902 & $520^{e}(c)$ & 639 & 781 & $d$ \\
\hline trispicMeen & & $537(1000)$ & 617 & 796 & 27,30 \\
\hline tpen & & $541(900)$ & 617 & 796 & 30 \\
\hline $\mathrm{S}^{\mathrm{Me} 2} \mathrm{~N}_{4}($ tren $)$ & & $452(2780)$ & & $784(-31)$ & 22 \\
\hline \multicolumn{6}{|c|}{ High-Spin Peroxo Complexes } \\
\hline $\mathrm{N} 4 \mathrm{Py}\left(\mathrm{Fe}-\mathrm{O}_{2}\right)$ & & $685(520)$ & $495(-17)$ & $827(-47)$ & $d$ \\
\hline trispicMeen $\left(\mathrm{Fe}-\mathrm{O}_{2}\right)$ & & $740(500)$ & 470 & 819 & 27,30 \\
\hline $\operatorname{tpen}\left(\mathrm{Fe}-\mathrm{O}_{2}\right)$ & & $755(450)$ & 470 & 817 & 30 \\
\hline $\operatorname{EDTA}\left(\mathrm{Fe}-\mathrm{O}_{2}\right)$ & & $520(520)^{f}$ & $459(-13)$ & $816(-40)$ & 53 \\
\hline bppa (Fe-OOH) & & $568(1200)^{e}$ & $621(-22)$ & $830(-17)$ & 21 \\
\hline oxyHr $(\mathrm{Fe}-\mathrm{OOH})$ & & $518(1800)^{f}$ & $503(-24)$ & $844(-48)$ & 54 \\
\hline $\mathrm{E} 47 \mathrm{~A} \mathrm{SOR}+\mathrm{H}_{2} \mathrm{O}_{2}\left(\mathrm{Fe}-\mathrm{OOH}\right.$ or $\left.\mathrm{Fe}-\mathrm{O}_{2}\right)$ & & $560(400)^{f}$ & $438(-23)$ & $850(-48)$ & 9 \\
\hline
\end{tabular}

${ }^{a}$ In $\mathrm{CH}_{3} \mathrm{CN}$ solvent. ${ }^{b}$ In $\mathrm{MeOH}$ solvent, unless otherwise indicated. ${ }^{c}$ Value not available due to incomplete formation of intermediate. ${ }^{d}$ This work. ${ }^{e}$ In acetone solvent. ${ }^{f}$ In water.

Table 2. Spin Hamiltonian Parameters for $\mathrm{Fe}^{\mathrm{III}}-\left(\eta^{1}-\mathrm{OOH}\right)$ and $\mathrm{Fe}^{\mathrm{III}}-\left(\eta^{2}-\mathrm{OO}\right)$ Complexes from EPR and Mössbauer Analysis

\begin{tabular}{|c|c|c|c|c|c|c|c|c|c|}
\hline complex & $S$ & $D, \mathrm{~cm}^{-1}$ & $E / D$ & $g_{1}, g_{2}, g_{3}$ & $A_{x}, A_{y}, A_{z}, \mathrm{MHz}$ & $\delta, \mathrm{mm} \mathrm{s}^{-1}$ & $\Delta E_{\mathrm{Q}}, \mathrm{mm} \mathrm{s}^{-1}$ & $\eta^{a}$ & ref \\
\hline$\left[\mathrm{Fe}(\mathrm{N} 4 \mathrm{Py})\left(\eta^{1}-\mathrm{OOH}\right)\right]^{2+}(\mathbf{1 a})$ & $1 / 2$ & & & $1.98,2.11,2.16^{a}$ & $-9(3),-53(2),+6(3)$ & $0.17(4)$ & $-1.6(1)^{b}$ & $\begin{array}{c}0.37 \\
\alpha=30^{\circ}\end{array}$ & this work \\
\hline$[\mathrm{Fe}(\text { trispicMeen })(\mathrm{OOH})]^{2+}$ & $1 / 2$ & & & $2.12,2.19,1.95$ & $10.6,-5.0,-56.3$ & 0.19 & -2.01 & $\begin{array}{c}0.4 \\
\alpha=43^{\circ}\end{array}$ & 31 \\
\hline$[\mathrm{Fe}(\text { bztpen })(\mathrm{OOH})]^{2+}$ & $1 / 2$ & & & $2.18,2.22,1.97$ & $-5.9,9.1,-57.9$ & 0.17 & -2.07 & $\begin{array}{c}0.26 \\
\alpha=64^{\circ}\end{array}$ & 56 \\
\hline activated bleomycin & $1 / 2$ & & & $2.17,2.26,1.94$ & $-48,5,5^{c}$ & $0.10(7)$ & $-3.0(2)$ & $\sim-3$ & 14 \\
\hline$\left[\mathrm{Fe}(\mathrm{N} 4 \mathrm{Py})\left(\eta^{2}-\mathrm{OO}\right)\right]^{+}(\mathbf{1 b})$ & $5 / 2$ & -1.0 & 0.11 & & $-29.5,-29.6,-27.8$ & 0.61 & 1.11 & $\begin{array}{c}0.57 \\
\alpha=30^{\circ}\end{array}$ & this work \\
\hline$\left[\mathrm{Fe}(\mathrm{EDTA})\left(\mathrm{O}_{2}\right)\right]^{3-}$ & $5 / 2$ & -1.0 & 0.21 & $2,2,2$ & $-31.7,-29.4,-28.5$ & 0.65 & 0.72 & 0.4 & 57 \\
\hline$\left[\mathrm{Fe}(\text { trispicMeen })\left(\mathrm{O}_{2}\right)\right]^{+}$ & $5 / 2$ & -1.7 & 0.08 & $2,2,2^{d}$ & $-31.1,-30.3,-28.0$ & 0.64 & 1.37 & 0.98 & 31 \\
\hline$\left[\mathrm{Fe}(\text { bztpen })\left(\mathrm{O}_{2}\right)\right]^{+}$ & $5 / 2$ & -0.9 & 0.08 & $2,2,2$ & $-27.8,-30.7,-27.8$ & 0.63 & 1.12 & 0.0 & 56 \\
\hline$\left[\mathrm{Fe}(\mathrm{OEP})\left(\mathrm{O}_{2}\right)\right]^{-}$ & $5 / 2$ & 0.85 & 0.29 & & $-31.9,-31.9,-31.9$ & 0.67 & 0.62 & 0.87 & 40 \\
\hline
\end{tabular}

$a g$ values of majority species. The relative orientations of the $\mathbf{g}$ - and A-tensors are not established by Mössbauer spectroscopy; therefore, we use different subscripts for these quantities. ${ }^{b} \Delta \mathrm{E}_{\mathrm{Q}}$ and $\eta$ are quoted in the principal axis frame of the efg-tensor (largest component along $\zeta$ ). The $\zeta$-axis of the efg coincides with the $y$-axis of the $\mathbf{A}$-tensor, and $\alpha$ rotates the efg around this $y$-axis. ${ }^{c}$ Table 1 of ref 14 contains two typographically errors: $\eta=3$ in column 1 should be replaced by $\eta=-3$, and $P=58.4$ (not 88.4) $\mathrm{MHz}$ in column 2 . ${ }^{d}$ Simaan et al. have added a quartic term to the $S=5 / 2$ spin Hamiltonian. ${ }^{31}$

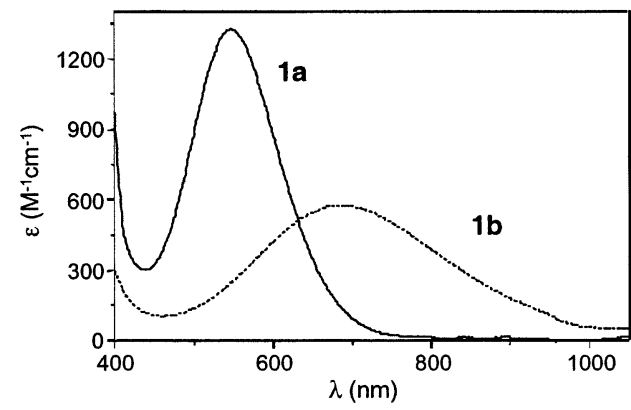

Figure 2. Visible spectra of $\mathbf{1 a}$ and $\mathbf{1 b}$ in methanol.

$v(\mathrm{Fe}-\mathrm{O})$ features in the $400-500 \mathrm{~cm}^{-1}$ region and $v(\mathrm{O}-$ O) features in the $815-900 \mathrm{~cm}^{-1}$ range..$^{20}$ The sole exception is high-spin $\left[\mathrm{Fe}^{\mathrm{III}}(\mathrm{bppa}) \mathrm{OOH}\right]$ with a $v(\mathrm{Fe}-\mathrm{O})$ of $621 \mathrm{~cm}^{-1}, 21$ like the low-spin complexes, and a $v(\mathrm{O}-\mathrm{O})$ of $830 \mathrm{~cm}^{-1}$, like the other high-spin complexes. According to DFT calculations, low-spin iron(III) hydroperoxo complexes have weaker $\mathrm{O}-\mathrm{O}$ bonds due to additional $\sigma$ interactions not available for a high-spin $\mathrm{Fe}(\mathrm{III})$ center between filled $\mathrm{O}-\mathrm{O}$

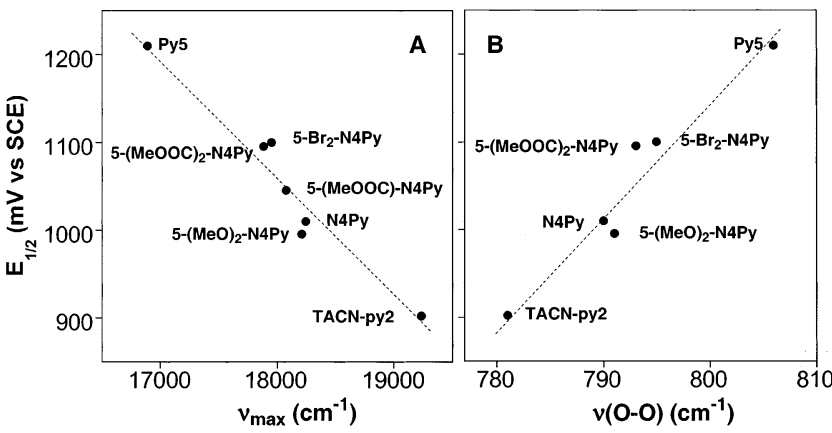

Figure 3. Correlation of the $\mathrm{Fe}^{\mathrm{III} / \mathrm{II}}$ potential of the iron(II) precursor complex with the energy of the charge-transfer transition (A) and the $v_{\mathrm{O}-\mathrm{O}}$ (B) observed for the corresponding $\mathrm{Fe}^{\mathrm{III}}-\mathrm{OOH}$ intermediate.

orbitals and an empty $\mathrm{e}_{\mathrm{g}}$ of the low-spin $\mathrm{Fe}$ (III) center. ${ }^{35-37}$ In support, Figure 3B shows the linear correlation between the $v(\mathrm{O}-\mathrm{O})$ and the redox potential of the parent $\mathrm{Fe}^{\mathrm{II}}$ complex with $v(\mathrm{O}-\mathrm{O})$ decreasing with redox potential. Thus, stabilization of the iron(III) oxidation state due to greater electron density at the metal center weakens the $\mathrm{O}-\mathrm{O}$ bond. 


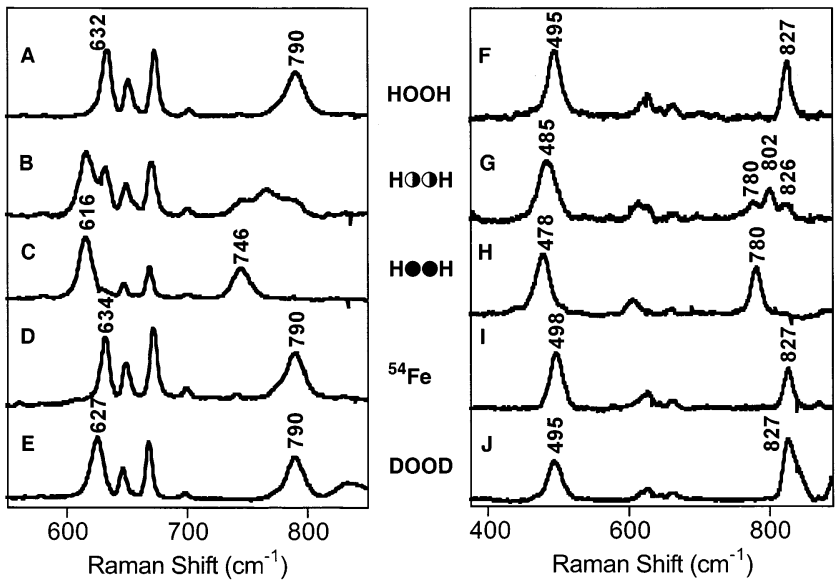

Figure 4. Resonance Raman spectra for $\mathbf{1 a}$ and $\mathbf{1 b}$ in methanol: (A) natural abundance 1a, (B) $1 \mathrm{a}$ made from $50 \%{ }^{18} \mathrm{O} \mathrm{H}_{2} \mathrm{O}_{2}$, (C) $\mathbf{1 a}$ made from $\mathrm{H}_{2}{ }^{18} \mathrm{O}_{2}$, (D) ${ }^{54} \mathrm{Fe}-1 \mathbf{a}$, (E) 1a made from $\mathrm{D}_{2} \mathrm{O}_{2}$, (F) natural abundance $\mathbf{1 b}$, (G) 1b made from $50 \%{ }^{18} \mathrm{O} \mathrm{H}_{2} \mathrm{O}_{2}$, (H) $\mathbf{1 b}$ made from $\mathrm{H}_{2}{ }^{18} \mathrm{O}_{2}$, (I) ${ }^{54} \mathrm{Fe}-\mathbf{1 b}$, (J) $1 \mathbf{b}$ made from $\mathrm{D}_{2} \mathrm{O}_{2}$.

\section{Scheme 2}

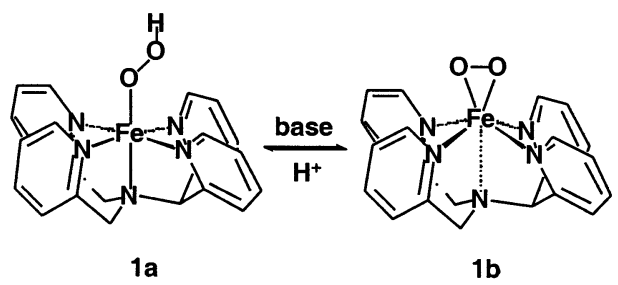

The notion that a low-spin iron(III) center can weaken the $\mathrm{O}-\mathrm{O}$ bond of a bound hydroperoxide ligand has previously been noted by Harris and Loew, who have studied the mechanisms of oxygen activation by cytochrome P450 with DFT calculations. ${ }^{33,34}$ This congruence of mechanistic ideas suggests that the chemistry of iron centers in heme and nonheme ligand environments may not be as distinct as first thought.

Detailed Spectroscopic Studies of $[\mathrm{Fe}(\mathrm{N} 4 \mathrm{Py}) \mathrm{OOH}]^{2+}$ (1a) and $\left[\mathrm{Fe}(\mathrm{N} 4 \mathrm{Py}) \mathrm{O}_{2}\right]^{+}$(1b). Detailed spectroscopic studies have been carried out on $[\mathrm{Fe}(\mathrm{N} 4 \mathrm{Py}) \mathrm{OOH}]^{2+}(\mathbf{1 a})$ as the prototype for this class of complexes to gain more insight into its structure and electronic properties. These properties are compared with those of its conjugate base [Fe(N4Py)$\left.\mathrm{O}_{2}\right]^{+}$(1) $)$, which is obtained by treating $\mathbf{1 a}$ with an appropriate base. This conversion is most readily observed by the change in color from purple to blue, corresponding to a shift of the $\lambda_{\max }$ from 548 to $685 \mathrm{~nm}$ and a decrease in $\epsilon$ (Figure 2). The molecular formulations for $\mathbf{1 a}$ and $\mathbf{1 b}$ have been established by electrospray mass spectrometry, affording molecular ions at $\mathrm{m} / \mathrm{z} 555$ and 455 corresponding to $\{[\mathrm{Fe}-$ $\left.(\mathrm{N} 4 \mathrm{Py})(\mathrm{OOH})] \mathrm{ClO}_{4}\right\}^{+}$and $\{[\mathrm{Fe}(\mathrm{N} 4 \mathrm{Py})(\mathrm{OO})]\}^{+}$, respectively, with the expected isotope distribution patterns. ${ }^{23,38}$ However, as elaborated below, the conversion from $\mathbf{1 a}$ to $\mathbf{1 b}$ is not a mere loss of a proton but entails a more significant change in structure and electronic properties (Scheme 2).

Resonance Raman Analysis. Resonance Raman studies of $\mathbf{1 a}$ and $\mathbf{1 b}$ involving detailed isotope labeling experiments are shown in Figures 4 and 5. As reported previously, ${ }^{24} \mathbf{1 a}$ exhibits four Raman features at 632, 652, 673, and $790 \mathrm{~cm}^{-1}$ (Figure 4A). Upon full ${ }^{18} \mathrm{O}$ substitution, the $790 \mathrm{~cm}^{-1}$ band

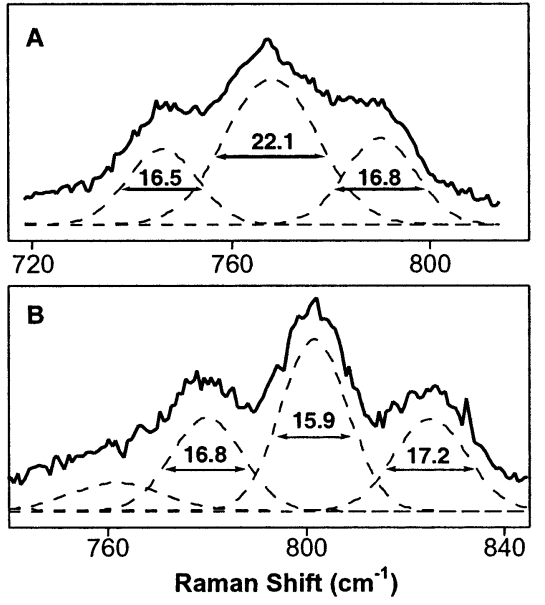

Figure 5. Deconvolution of the $v(\mathrm{O}-\mathrm{O})$ features of $\mathbf{1 a}(\mathrm{A})$ and $\mathbf{1 b}(\mathrm{B})$ obtained from $50 \%{ }^{18} \mathrm{O}$-enriched $\mathrm{H}_{2} \mathrm{O}_{2}$.

downshifts to $746 \mathrm{~cm}^{-1}$, the $44 \mathrm{~cm}^{-1}$ downshift fully consistent with that predicted by Hooke's law for $v(\mathrm{O}-\mathrm{O})$ (Figure 4C). This feature is unaffected by the introduction of ${ }^{54} \mathrm{Fe}$ or ${ }^{2} \mathrm{H}$, supporting its principal assignment as the $\mathrm{O}-\mathrm{O}$ stretch (Figures 4D and 4E). On the other hand, the $632 \mathrm{~cm}^{-1}$ band downshifts $16 \mathrm{~cm}^{-1}$ with the use of $\mathrm{H}_{2}{ }^{18} \mathrm{O}_{2}$ and upshifts $2 \mathrm{~cm}^{-1}$ with ${ }^{54} \mathrm{Fe}$. The Hooke's law calculations based on a simple $v(\mathrm{Fe}-\mathrm{O})$ assignment predict a $28 \mathrm{~cm}^{-1}$ downshift and a $3 \mathrm{~cm}^{-1}$ upshift, respectively, suggesting that this mode involves more than a diatomic $\mathrm{Fe}-\mathrm{O}$ stretching deformation. Indeed, the use of $\mathrm{D}_{2} \mathrm{O}$ induces a downshift of $5 \mathrm{~cm}^{-1}$, indicating that the entire hydroperoxide ligand contributes to this mode. From a normal coordinate analysis based on this information, the $790 \mathrm{~cm}^{-1}$ band is assigned principally to the $v(\mathrm{O}-\mathrm{O})(76 \%)$ admixed with $15 \% v(\mathrm{Fe}-\mathrm{O})$ and the $632 \mathrm{~cm}^{-1}$ band to a combination of the $v(\mathrm{Fe}-\mathrm{O})(62 \%)$, the $\delta(\mathrm{Fe}-\mathrm{O}-\mathrm{O})(23 \%)$, and the $v(\mathrm{O}-\mathrm{O})(7 \%){ }^{37}$

The features at 652 and $673 \mathrm{~cm}^{-1}$ do not shift significantly with the use of $\mathrm{H}_{2}{ }^{18} \mathrm{O}_{2}$, showing that they are not peroxidederived modes. However, their intensities decrease noticeably upon ${ }^{18} \mathrm{O}$ substitution. These two bands are unassigned modes that gain resonance intensity from mixing with the $632 \mathrm{~cm}^{-1}$ band. ${ }^{37}$ The extent of mixing decreases significantly with the downshift of the $632 \mathrm{~cm}^{-1}$ band to $616 \mathrm{~cm}^{-1}$, resulting in the loss of intensity for the two unassigned modes. Concomitantly the $616 \mathrm{~cm}^{-1}$ band grows in intensity (Figure 4C). Curve fitting of spectra $\mathrm{A}$ and $\mathrm{C}$ in Figure 4 shows that the $v(\mathrm{Fe}-\mathrm{OOH}) / v(\mathrm{O}-\mathrm{O})$ peak area ratio is about twice as large for the ${ }^{18} \mathrm{O}$ isotopomer as for the ${ }^{16} \mathrm{O}$ isotopomer.

The resonance Raman spectrum of $\mathbf{1 a}$ derived from $50 \%$ ${ }^{18} \mathrm{O}$-labeled $\mathrm{H}_{2} \mathrm{O}_{2}$ (Figure 4B) supports the above assignments. The $632 \mathrm{~cm}^{-1}$ feature splits only into two bands with energies and intensities corresponding to those observed for the pure isotopomers. The $790 \mathrm{~cm}^{-1}$ feature, on the other hand, splits into three bands at 746, 768, and $790 \mathrm{~cm}^{-1}$, corresponding to the respective $\mathrm{O}-\mathrm{O}$ stretching vibrations of the ${ }^{18} \mathrm{O}^{18} \mathrm{O},{ }^{16} \mathrm{O}^{18} \mathrm{O}$, and ${ }^{16} \mathrm{O}^{16} \mathrm{O}$ isotopomers. Curve fitting of these three features affords an area ratio of approximately 1:2:1 (Figure 5A), corresponding to that found by Raman spectroscopy for the labeled $\mathrm{H}_{2} \mathrm{O}_{2}$ prior to complex forma- 
tion. The line width at half-height for the $768 \mathrm{~cm}^{-1}$ band is about 1.5 times broader than those associated with the two pure isotopomers, indicative of more than one feature arising from the ${ }^{16} \mathrm{O}^{18} \mathrm{O}$ isotopomer. The larger line width for the ${ }^{16} \mathrm{O}^{18} \mathrm{O}$ band can be rationalized by taking into account the unresolved contributions from the $\mathrm{Fe}-{ }^{16} \mathrm{O}^{18} \mathrm{OH}$ and the $\mathrm{Fe}-$ ${ }^{18} \mathrm{O}^{16} \mathrm{OH}$ isotopomers, predicted by normal coordinate analysis to be at 775 and $764 \mathrm{~cm}^{-1}$, respectively. ${ }^{37}$ Thus these results provide strong evidence for a terminally bound hydroperoxide in $\mathbf{1 a}$.

Corresponding Raman analysis of $\mathbf{1 b}$ shows that the peroxo moiety in this species is coordinated in a significantly different mode. Its Raman spectrum exhibits two intense features at 495 and $827 \mathrm{~cm}^{-1}$ (Figure 4F) similar to features observed for $\left[\mathrm{Fe}(\mathrm{EDTA})\left(\mathrm{O}_{2}\right)\right]^{3-},\left[\mathrm{Fe}(\text { tpen }) \mathrm{O}_{2}\right]^{+}$, and $[\mathrm{Fe}-$ (trispicMeen) $\left.\mathrm{O}_{2}\right]^{+}$(Table 1 ). These bands respectively downshift by 17 and $47 \mathrm{~cm}^{-1}$ upon ${ }^{18} \mathrm{O}$ substitution (Figure $4 \mathrm{H}$ ) but are unaffected by introduction of $\mathrm{D}_{2} \mathrm{O}$ (Figure $4 \mathrm{~J}$ ). Furthermore, ${ }^{54} \mathrm{Fe}$ substitution only affects the $495 \mathrm{~cm}^{-1}$ band, resulting in an upshift of $3 \mathrm{~cm}^{-1}$ (Figure 4I). Hooke's law calculations indicate that these shifts are fully consistent with the assignment of the observed bands to $v(\mathrm{Fe}-\mathrm{O})$ and $v(\mathrm{O}-\mathrm{O})$ modes, respectively.

As with 1a, the resonance Raman spectrum of $\mathbf{1 b}$ derived from $50 \%{ }^{18} \mathrm{O}$-labeled $\mathrm{H}_{2} \mathrm{O}_{2}$ (Figure $4 \mathrm{G}$ ) provides insights into the nature of the intermediate. The $v(\mathrm{O}-\mathrm{O})$ band splits into three peaks at 780,802 , and $826 \mathrm{~cm}^{-1}$ of comparable line width with a 1:2:1 peak area ratio (from curve fitting) (Figure 5B). This is exactly the pattern expected for a symmetrically bound peroxide. Since mass spectral data and EPR and Mössbauer analysis (see below) favor a mononuclear formulation, $\mathbf{1 b}$ is proposed to be an iron $-\eta^{2}$-peroxo complex.

The behavior of the $495 \mathrm{~cm}^{-1}$ band of $\mathbf{1 b}$ generated with mixed labeled $\mathrm{H}_{2} \mathrm{O}_{2}$ differs from that of the $632 \mathrm{~cm}^{-1}$ band of 1a. The former shifts (Figure 4G) to an energy, namely, $485 \mathrm{~cm}^{-1}$, that is intermediate between the ${ }^{16} \mathrm{O}$ and the ${ }^{18} \mathrm{O}$ extremes, rather than splitting into two peaks corresponding to these two extremes, as observed for 1a (Figure 4B). This observation suggests that the $495 \mathrm{~cm}^{-1}$ mode is not a diatomic mode but a triatomic vibration involving the $\mathrm{Fe}$ and the two peroxide oxygens, most plausibly the symmetric combination for stretching the two $\mathrm{Fe}-\mathrm{O}$ bonds. The 485 $\mathrm{cm}^{-1}$ band would then be associated with the unresolved contributions from the three isotopomers $\mathrm{Fe}^{16} \mathrm{O}_{2}, \mathrm{Fe}^{16} \mathrm{O}^{18} \mathrm{O}$, and $\mathrm{Fe}^{18} \mathrm{O}_{2}$.

EPR and Mössbauer Analysis of 1a. Figure 6 shows EPR spectra of $1 \mathrm{a}$ in frozen methanol solution, containing $\mathrm{Fe}$ in natural abundance (A) and enriched to $95 \%{ }^{57} \mathrm{Fe}(\mathrm{B})$. The spectrum of Figure 6A consists of two distinct, but nevertheless quite similar, species with $g$ values at $g_{x}=1.98, g_{y}=$ 2.11, $g_{z}=2.16(66 \%)$ and $g_{x}=1.98, g_{y}=2.12$, and $g_{z}=$ $2.17(34 \%)$. Presently the coordinate labels are arbitrary; below we relate them to the structure of 1a. Similar spectra have been reported for $\mathbf{1 a}$ dissolved in acetone; ${ }^{25}$ close inspection of the published spectrum reveals also the presence of two similar species, with $g$ values that differ slightly from those obtained here.

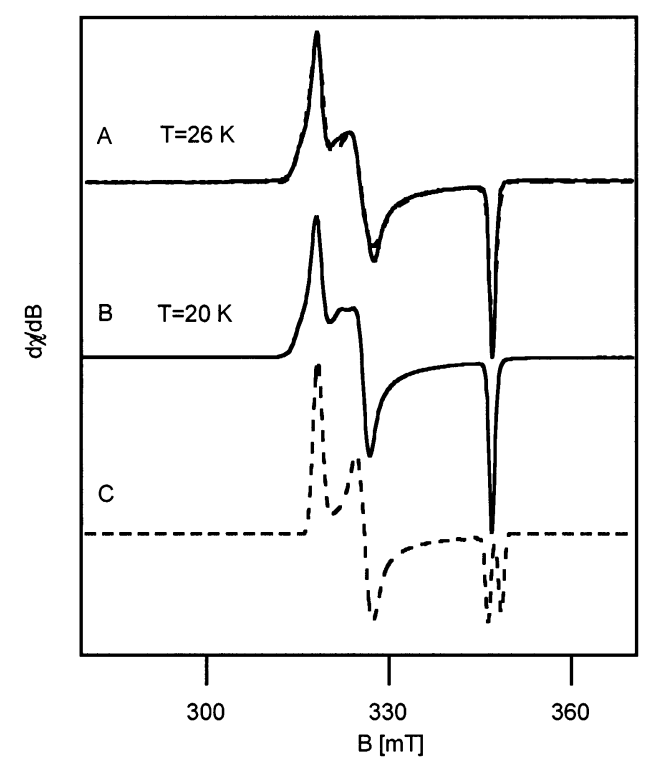

Figure 6. X-band EPR spectra of 1a in methanol recorded for a sample containing ${ }^{57} \mathrm{Fe}$ in natural abundance $(\mathrm{A}, T=26 \mathrm{~K}$ ) and enriched to $95 \%$ $(\mathrm{B}, T=20 \mathrm{~K})$. The dotted line drawn through the data of (A) is a spectral simulation for two species with $g_{x}=1.98, \mathrm{~g}_{y}=2.11, \mathrm{~g}_{z}=2.16$ and $\sigma_{x}=$ $0.001, \sigma_{y}=0.005, \sigma_{z}=0.005(66 \%)$ and $g_{x}=1.98, \mathrm{~g}_{y}=2.12, \mathrm{~g}_{z}=2.17$ and $\sigma_{x}=0.004, \sigma_{y}=0.008, \sigma_{z}=0.007(34 \%)$, where the $\sigma_{n}$ describe the Gaussian widths of assumed distributed $g$ values. Spectra were recorded under nonsaturating conditions. (C) A spectral simulation, using the width parameters of spectrum $\mathrm{A}$, and assuming a principal axis component $A_{x}=$ $53 \mathrm{MHz}$ along $g_{x}$ as suggested by application of the Griffith model for rhombic symmetry. In all simulations the packet line was assumed to be a Lorentzian with full width $0.4 \mathrm{mT}$. Microwave power was $2 \mathrm{~mW}$ and the modulation amplitude $1 \mathrm{mT}$ for spectra A and B.

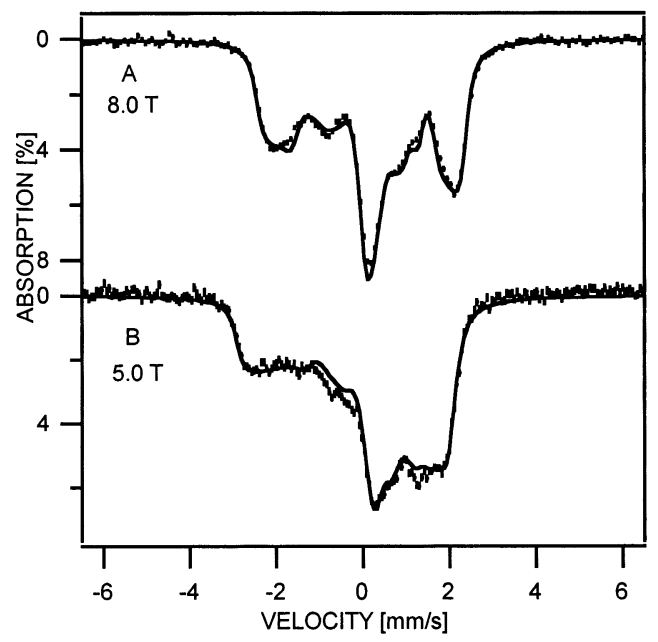

Figure 7. Mössbauer spectra of $\mathbf{1 a}$ in methanol recorded at $1.5 \mathrm{~K}$ in parallel applied fields of $8.0 \mathrm{~T}(\mathrm{~A})$ and $5.0 \mathrm{~T}(\mathrm{~B})$. The solid lines are spectral simulations based on eq 1 using the parameters listed in Table 2.

Figure 7 shows Mössbauer spectra of a $5 \mathrm{mM}{ }^{57} \mathrm{Fe}-$ enriched sample of $\mathbf{1 a}$ dissolved in methanol. The spectra were recorded at $1.5 \mathrm{~K}$ in magnetic fields of $8.0 \mathrm{~T}(\mathrm{~A})$ and 5.0 T (B) applied parallel to the observed $\gamma$-radiation. In an applied field of $0.05 \mathrm{~T}$ the $4.2 \mathrm{~K}$ spectrum consisted of a broadened and asymmetric quadrupole doublet, suggesting spin-spin interactions; the spectra shown in Figure 7 were recorded under conditions where these interactions do not affect the spectral shapes. The low-temperature spectra of 1a shown have features typical of low-spin iron(III) com- 
plexes, i.e., they exhibit broad features characteristic of an $S=1 / 2$ system with an isotropic Zeeman interaction and a very anisotropic A-tensor. At $100 \mathrm{~K}$, and in zero field, we observed an asymmetric doublet with $\Delta E_{\mathrm{Q}}=1.58(6) \mathrm{mm} / \mathrm{s}$ and $\delta=0.20(5) \mathrm{mm} / \mathrm{s}$. These parameters are also consistent with a low-spin complex.

We have evaluated the spectra of Figure 7 using the spin Hamiltonian

$$
\begin{aligned}
& H=\beta \hat{\mathbf{S}} \cdot \mathbf{g} \cdot \mathbf{B}+\hat{\mathbf{S}} \cdot \mathbf{A} \cdot \hat{\mathbf{I}}-g_{n} \beta_{n} \hat{\mathbf{I}} \cdot \mathbf{B}+H_{\mathrm{Q}} \\
& \left.H_{\mathrm{Q}}=\frac{e Q V_{\zeta \xi}}{12} 3 \hat{I}_{\zeta}^{2}-\frac{15}{4}+\eta\left(\hat{I}_{\xi}^{2}-\hat{I}_{\eta}^{2}\right)\right]
\end{aligned}
$$

where all symbols have their conventional meanings. The quadrupole interaction, is written in the principal axis frame $(\xi, \eta, \zeta)$ of the electric field gradient (efg) tensor. It is reasonable to assume that the two (nearly identical) species indicated by EPR produce indistinguishable Mössbauer spectra, and we have therefore simulated the spectra by assuming the presence of only one species. Because the electronic g-tensor is essentially isotropic, the Mössbauer spectra obtained for frozen solution samples are insensitive to the orientation of the A-tensor relative to the g-tensor; however, the spectra are very sensitive to the relative orientation of the A- and efg-tensors. The solid lines drawn through the data are theoretical curves based on eq 1 using the parameters listed in Table 2. The simulations reveal the following features. First, the A-tensor has one large component, $A_{y}=-53 \mathrm{MHz}$, and two smaller components, $A_{z}=$ $+6 \mathrm{MHz}$ and $A_{x}=-9 \mathrm{MHz}$. Second, the largest component of the efg-tensor, $V_{\zeta \zeta}$, is negative and along the $y$-axis of the A-tensor. The EFG is nonaxial, $\eta=\left(V_{\xi \xi}-V_{\eta \eta}\right) / V_{\zeta \xi}=0.37$, and rotated by approximately $30^{\circ}$ around the $y$-axis.

For porphyrins and a variety of other low-spin complexes Mössbauer and EPR data have been analyzed successfully in the framework of the hole model proposed by Griffith ${ }^{58}$ and amended by Oosterhuis and Lang. ${ }^{59}$ In this model one can analyze the experimental $g$ values to obtain the ligand field parameters $\Delta / \lambda$ and $V / \lambda$, where $\Delta$ and $V$ respectively describe the axial and rhombic splittings of the $t_{2 \mathrm{~g}}$ orbitals, and $\lambda \approx 380 \mathrm{~cm}^{-1}$ is the spin-orbit coupling constant. From this analysis one can calculate the components of the ${ }^{57} \mathrm{Fe}$ A-tensor using suitable scaling factors ( $\kappa$ for the contact term and $\left.P=2 g_{n} \beta_{n}\left\langle r^{-3}\right\rangle\right) .{ }^{59}$ With the assumption that the site symmetry is not lower than rhombic, we have performed such an analysis and found that the largest component of the A-tensor should be along the direction defined by the EPR resonance at $g_{\min }=1.98$. Because the EPR lines are quite narrow, e.g., $0.45 \mathrm{mT}$ at $g=1.98$, this hypothesis can readily be tested by studying the EPR spectra for an ${ }^{57} \mathrm{Fe}$ enriched solution sample. The spectral simulation of Figure $6 \mathrm{C}$ shows that the $g=1.98$ resonance would be significantly

(56) Horner, O.; Jeandey, C.; Oddou, J.-L.; Bonville, P.; McKenzie, C. J.; Latour, J.-M. Eur. J. Inorg. Chem. 2002, 3278-3283.

(57) Horner, O.; Jeandey, C.; Oddou, J.-L.; Bonville, P.; Latour, J.-M. Eur. J. Inorg. Chem. 2002, 1186-1189.

(58) Griffith, J. S. Nature 1957, 180, 30

(59) Oosterhuis, W. T.; Lang, G. Phys. Rev. 1969, 178, 439-456. split if $A_{y}=-53 \mathrm{MHz}$ were along the $g_{\min }=1.98$ direction. A comparison of the simulated spectrum with the experimental data, Figure 6B, shows that the $53 \mathrm{MHz}$ component of the A-tensor cannot be along this direction. Spectral simulations suggest that that the component of the $\mathbf{A}$-tensor along the $g_{\min }=1.98$ direction can be at most only $12 \mathrm{MHz}$. Thus, the A-tensor of 1a is oriented such that its largest component is close to the plane defined by the principal axis components $g_{\text {mid }}$ and $g_{\max }$. It follows that the data are not compatible with a site of rhombic symmetry, as is often tacitly assumed by applying the Griffith model.

Density functional theory (DFT) calculations of 1a provide an explanation of the experimental results. For complexes having $g$ values close to $g=2$, as is the case for $\mathbf{1 a}$, one can use second-order perturbation expressions ${ }^{17}$ to extract $\Delta$ and $V$ from the $g$-shifts, namely,

$$
\begin{gathered}
\Delta g_{i}=g_{i}-2 \\
\Delta g_{z}=\Delta g_{\text {max }}=2 \lambda / \mathrm{V} \\
\Delta g_{y}=\Delta g_{\text {mid }}=4 \lambda /(2 \Delta+V)
\end{gathered}
$$

From the $g$ values of the major component of $1 \mathbf{a}$ we obtain, using $\lambda=380 \mathrm{~cm}^{-1}, \Delta=4535 \mathrm{~cm}^{-1}$ and $V=4750 \mathrm{~cm}^{-1}$, in agreement with the $\mathrm{t}_{2 \mathrm{~g}}$ splitting (corresponding to $\Delta+$ $V / 2$ ) of ca. $6200 \mathrm{~cm}^{-1}$ obtained from magnetic circular dichroism experiments. ${ }^{37}$ Solomon and co-workers have optimized the geometry of $\mathbf{1 a}$ (see Figure 1 of the Supporting Information of ref 37) using the hybrid B3LYP density functional and the pseudo potential adapted basis set LanL2DZ provided by the Gaussian 98 package, and we have performed similar calculations using a larger basis set, Wachters $(+\mathrm{f})$ on iron and $6-311 \mathrm{G}$ on the ligand atoms. The calculated structures are in good agreement and consistent with our EXAFS data (see below). Most interestingly, the calculations show that the hydroperoxo ligand binds with bond angle $\angle \mathrm{Fe}-\mathrm{O}-\mathrm{O} \approx 116^{\circ}$ such that the projection of the $\mathrm{O}-\mathrm{O}$ vector on the plane $(x-y)$ defined by the four pyridine nitrogens bisects (within $2^{\circ}$ ) the $\mathrm{N}($ py) $-\mathrm{Fe}-\mathrm{N}($ py) angle. The $\pi_{\mathrm{v}}{ }^{*}$ orbital of the $\mathrm{OOH}^{-}$ligand interacts with the singly occupied $d_{x z}$ orbital in a coordinate system where $y$ is along the mentioned bisector (for nomenclature of orbital states and contour plots of molecular orbitals see ref 37 ). This interaction is likely the major determinant defining the rhombic potential to be used in the Griffith model.

For 1a the four equatorial pyridine nitrogens, the axial amine, and the proximal $\mathrm{O}$ atom of the peroxo ligand (roughly) define the octahedral component of the ligand field. The $\mathrm{d}_{x z}-\pi_{\mathrm{v}} *$ interaction produces a rhombic component that is rotated relative to the cubic frame by $\gamma \approx 45^{\circ}$ about the $z$-axis (which is taken along the $\mathrm{Fe}-\mathrm{N}$ (amine) vector). Oosterhuis and Lang have given expressions for the $\mathbf{g -}, \mathbf{A}-$, and efg-tensors for the case where the rhombic field is rotated by an angle $\gamma$ about the $z$-axis,${ }^{59}$ creating a site corresponding to monoclinic symmetry. Their treatment shows that the g-tensor rotates backward through $\gamma=-45^{\circ}$ about $z$, while the efg-tensor follows the rhombic field (the $g$ values still depend only on $\Delta / \lambda$ and $V / \lambda$ ). The anisotropy of the A-tensor 
results from spin-dipolar, $\mathbf{A}(\mathrm{sd})$, and orbital contributions. Since the latter are proportional to $\left(g_{i}-2\right)$ and thus small, the principal axis frame of $\mathbf{A}$ will be determined (roughly) by $\mathbf{A}(\mathrm{sd})$. For $\gamma=45^{\circ}$, as suggested by the DFT calculations, the $\mathbf{A}$ - and efg-tensors will be rotated by $2 \gamma=90^{\circ}$ relative to the $\mathbf{g}$-tensor, which moves the largest component of $\mathbf{A}$ from $g_{\min }=g_{x}$ to $g_{\text {mid }}=g_{y}$, reconciling the model with the EPR observation. The preceding analysis is supported by our DFT calculations (see below) which show that the projection of largest components of the A- and efg-tensors into the $x y$ plane are within $1^{\circ}$ along $y$.

From the experimental $g$ values of 1a we have calculated the orbital reduction factor, $k=0.85$, the mixing coefficients $a=0.035, b=0.998$, and $c=0.048$ of the Griffith model and, using $P=70 \mathrm{MHz}$ and $\kappa=0.38$ in eq 10 of Oosterhuis and Lang, ${ }^{59}$ the $\mathbf{A}$-tensor components for $\gamma=45^{\circ}$, obtaining $A_{x}=-7.6(-9) \mathrm{MHz}, A_{y}=-53.5(-53) \mathrm{MHz}$, and $A_{z}=$ $+4.7(+6) \mathrm{MHz}$, in excellent agreement with the experimental data (listed in parentheses). The components of the spin-dipolar term calculate as $A_{x}(\mathrm{sd})=+19.1 \mathrm{MHz}, A_{y}(\mathrm{sd})$ $=-36.8 \mathrm{MHz}$, and $A_{z}(\mathrm{sd})=+17.7 \mathrm{MHz}$, which compares with $A_{x^{\prime}}(\mathrm{sd})=+13 \mathrm{MHz}, A_{y^{\prime}}(\mathrm{sd})=-32.3 \mathrm{MHz}$, and $A_{z^{\prime}}$ $(\mathrm{sd})=+19 \mathrm{MHz}$ obtained from our DFT calculations. We have used the primed coordinates because the principal axis frame of $\mathbf{A}(\mathrm{sd})$ does not quite coincide with the frame $x, y, z$ (the $z^{\prime}$-axis is tilted in the $y z$-plane by $18^{\circ}$ relative to our octahedral $z$-axis). In fact, the DFT geometry optimization indicated $C_{1}$ symmetry (but approximately $C_{s}$ ), and under these circumstances the magnetic hyperfine interactions would acquire antisymmetric components, introducing unknowns that cannot be determined given the limited resolution of the Mössbauer spectra.

Time dependent DFT calculations of $\mathbf{1 a}$ are best presented in a coordinate system for which the $z$-axis is along the $\mathrm{Fe}-$ $\mathrm{N}$ (amine) bond and the $y$-axis along the projection of the $\mathrm{O}-\mathrm{O}$ vector into the (approximate) plane defined by the four $\mathrm{N}$ (py) atoms; in this frame the d orbitals $x z, y z$, and $x^{2}-y^{2}$ belong to the $t_{2 g}$ set. Our calculations reveal the lowest level to be $y z$, with the first excited states at $2000 \mathrm{~cm}^{-1}\left(x^{2}-y^{2}\right)$ and $7500 \mathrm{~cm}^{-1}(x z)$; the latter orbital contains the unpaired electron. These calculations agree very well with those of Lehnert et al. (717 and $7750 \mathrm{~cm}^{-1}$ ) for a simplified [Fe$\left.\left(\mathrm{NH}_{3}\right)_{5}(\mathrm{OOH})\right]$ model for $\mathbf{1 a} .^{37}$ The EPR analysis predicts an orbital splitting of $6900 \mathrm{~cm}^{-1}\left(6450 \mathrm{~cm}^{-1}\right.$ for the slightly different $g$ values (obtained in acetone solution) of Lehnert et $\left.a l .{ }^{37}\right)$. The Griffith model prefers $y z$ to be at higher energy than $x^{2}-y^{2}$ (providing a better match with the experimental A-tensor). However, it is unrealistic to expect that TD-DFT theory provides excitation energies with an accuracy better than $2000 \mathrm{~cm}^{-1}$. Our calculated quadrupole splitting for $\mathbf{1 a}$, $\Delta E_{\mathrm{Q}}=-1.76 \mathrm{~mm} / \mathrm{s}$, matches the experimental data within the uncertainties; the calculated value $\eta=0.13$ is also compatible with our data. The efg-tensor contains a substantial ligand contribution $\left(\Delta E_{\mathrm{Q}}=-0.60 \mathrm{~mm} / \mathrm{s}\right.$, major component along $z, \eta=0.33$ ) as was verified by calculating the efg for a $\mathrm{Ga}(\mathrm{III})$ complex constrained to the geometry of the optimized 1a structure. Overall, our analysis and the

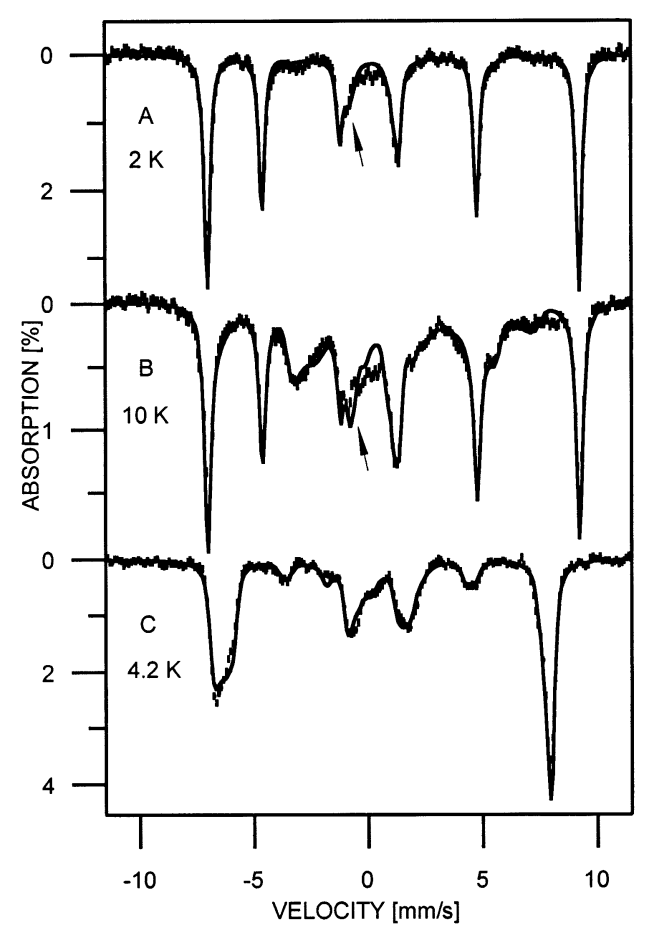

Figure 8. Mössbauer spectra of $\mathbf{1 b}$ in methanol recorded in parallel applied fields of $0.05 \mathrm{~T}(\mathrm{~A}$ and $\mathrm{B}$ ) and $8.0 \mathrm{~T}(\mathrm{C})$ at the temperatures indicated. For clarity we have removed from the data the contribution $(8 \%$ of total $\mathrm{Fe})$ of a high-spin iron(III) contaminant. The majority species (ca. $86 \%$ of the iron) belongs to the blue peroxo species identified by optical spectroscopy. The sample contains a diamagnetic contaminant that appears in A and B as a quadrupole doublet; its low-energy line appears as a shoulder and is indicated by the arrows. The solid lines are spectral simulations based on eq 3 using the parameters listed in Table 2. The simulations include also the contribution of the diamagnetic species.

complementary analysis of Lehnert et al. ${ }^{37}$ provide a very good description of the experimental data.

Finally, we wish to comment briefly on the sign of the $g$ values of 1a. As demonstrated previously for cytochrome $c_{3},{ }^{60}$ the sign of the product $g_{x} g_{y} g_{z}$ can be determined from the Mössbauer spectra in the framework of the Griffith model. A similar analysis (not shown) performed for 1a shows that $g_{x} g_{y} g_{z}>0$. This result, of course, was anticipated from the MCD studies of Solomon and co-workers. ${ }^{37}$ Thus, for the given magnitudes of the $g$ values the solution for $g_{x} g_{y} g_{z}<0$ corresponds to the situation where the $\mathrm{t}_{2 \mathrm{~g}}$ splittings are smaller than the spin-orbit coupling constant. In view of the presence of the $t_{2 g} \rightarrow t_{2 g}$ transition at $\approx 6200 \mathrm{~cm}^{-1}$, it follows that the energy separation between the $x z$ orbital and at least one other member of the $t_{2 g}$ set is large compared to the spin-orbit coupling constant.

EPR and Mössbauer Analysis of 1b. Figures 8 and 9 show Mössbauer and EPR spectra of $\mathbf{1 b}$ in frozen methanol solution. Both spectroscopic techniques show unambiguously that the blue complex $\mathbf{1 b}$ is high-spin iron(III). As shown below complex $\mathbf{1 b}$ has a zero-field splitting parameter $D \approx$ $-1 \mathrm{~cm}^{-1}$. For this value of $D$ all three Kramers doublets of the $S=5 / 2$ system (see Figure 10) are substantially populated at $10 \mathrm{~K}$. The $2 \mathrm{~K}$ Mössbauer spectrum of Figure $8 \mathrm{~A}$ provides

(60) Huynh, B. H.; Emptage, M. H.; Münck, E. Biochim. Biophys. Acta 1978, 534, 295-306. 


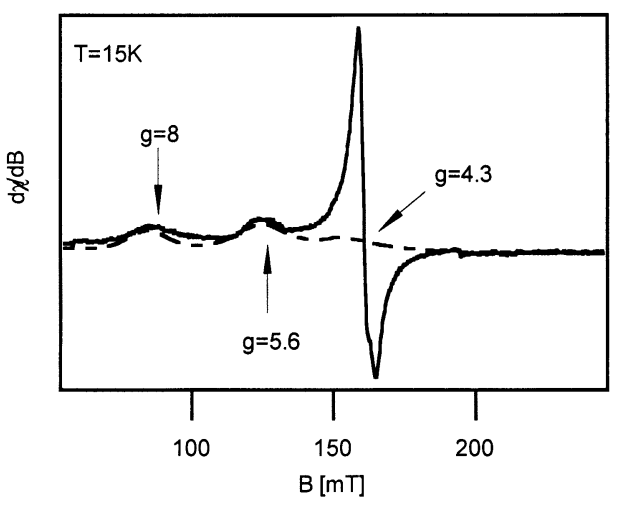

Figure 9. X-band EPR spectum of $\mathbf{1 b}$ in methanol recorded at $15 \mathrm{~K}$. The dotted line is a spectral simulation of the high-spin iron(III) peroxo species. In order to account for the line shape we assumed for the simulation an average $E / D=0.22$ distributed by $\sigma_{E / D}=0.012$; the feature of the upward pointing arrow indicates the $g=5.6$ feature of the middle Kramers doublet, while the downward arrows identify the $g_{y}$ and $g_{x}$ features of the upper doublet. For the given $E / D$ distribution the $g_{y}$ feature is sufficiently broadened to be almost imperceptible. While the $g=4.3$ feature dominates the figure, this species accounts for only $8 \%$ of the total $\mathrm{Fe}$.

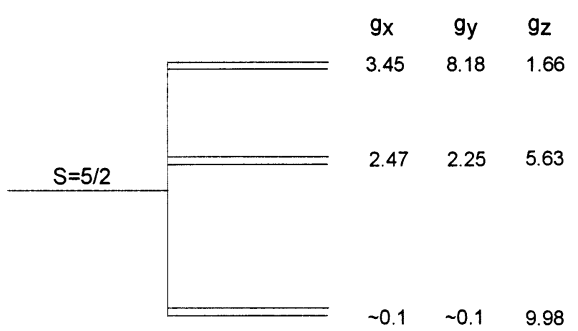

Figure 10. Calculated $g$ values for the $S=5 / 2$ center $(E / D=0.11)$ of $\mathbf{1 b}$.

the best point of departure for analyzing the spectra. At this temperature essentially only the ground Kramers doublet $(\approx 95 \%)$ of $1 \mathrm{~b}$ is populated. The sample of Figure 8 contained contributions from three different species. The majority species, accounting for ca. $86-88 \%$ of the total $\mathrm{Fe}$ in the sample, gives rise to the conspicuous six-line pattern in Figure 8A. A second $S=5 / 2$ species, associated with the $g$ $\approx 4.3$ species of Figure 9, accounts for ca. $8 \%$ of the iron. This species also produces a simple six-line pattern at $2 \mathrm{~K}$. An earlier preparation contained ca. $40 \%$ of this contaminant (probably a decay product), and from a study of that preparation its spectral features are known reasonably well. For clarity we have subtracted its contribution from the data shown in Figure 8. The sample of Figure 8 contains a third species, accounting for $6 \%$ of total $\mathrm{Fe}$, that contributes a doublet with quadrupole splitting $\Delta E_{\mathrm{Q}}=2.1 \mathrm{~mm} / \mathrm{s}$ and isomer shift $\delta=0.24 \mathrm{~mm} / \mathrm{s}$. This species behaves like a diamagnet, and we suspect that it represents some low-spin $\mathrm{Fe}^{\mathrm{III}} \mathrm{Fe}^{\mathrm{III}}$ contaminant; spectral simulations for this species are included in spectra B and C of Figure 8.

The intensity pattern of the $2 \mathrm{~K}$ Mössbauer spectrum reveals that the electronic ground state is a Kramers doublet with extremely anisotropic $g$ values, e.g., $g_{z} \gg g_{x} \approx g_{y}$. Such a doublet occurs for an $S=5 / 2$ system for $D<0$ and $E / D$ $<0.20$. We have simulated the spectra of Figure 8 with the spin Hamiltonian

$$
\begin{aligned}
H=D\left[\hat{S}_{z}{ }^{2}-\frac{1}{3} S(S+1)\right]+E\left(\hat{S}_{x}^{2}-\hat{S}_{y}{ }^{2}\right)+2 \beta \hat{\mathbf{S}} \cdot \mathbf{B}+ \\
\hat{\mathbf{S}} \cdot \mathbf{A} \cdot \hat{\mathbf{I}}-g_{n} \beta_{n} \hat{\mathbf{I}} \cdot \mathbf{B}+H_{\mathrm{Q}}
\end{aligned}
$$

A fit of the $2 \mathrm{~K}$ spectrum to eq 6 yielded $A_{z}=-27.8(2)$ $\mathrm{MHz}$ and $\delta=0.61(2) \mathrm{mm} / \mathrm{s}$, which we associate with the blue species seen with optical spectroscopy. Moreover, the intensity of this component diminishes when $\mathbf{1 b}$ is allowed to decay. High-spin iron(III) complexes exhibit in general isotropic magnetic hyperfine interactions. However, the 8.0 T spectra of Figure 8C cannot be fit unless some anisotropy of the A-tensor is admitted; from simultaneous fits to the spectra of Figure $8 \mathrm{~A}$ and Figure $8 \mathrm{~B}$ we found that $A_{x} \approx$ $-29.5(8) \mathrm{MHz}$ and $A_{y}=-29.6(5) \mathrm{MHz}$. The 8.0 T spectrum also provides a good estimate of the zero-field splitting parameter $D$, namely, $D=-1.0(2) \mathrm{cm}^{-1}$. The $10 \mathrm{~K}$ Mössbauer spectrum of complex $\mathbf{1 b}$ has contributions from all three Kramers doublets of the $S=5 / 2$ state. Initially we suspected that the $g=4.3$ species observed by EPR was associated with $\mathbf{1 b}$. However, fits to the $10 \mathrm{~K}$ Mössbauer spectra failed to account for the shape of the spectrum associated with the middle Kramers doublet, unless the rhombicity parameter $E / D$ was chosen to be smaller than 0.15 . Thus the blue peroxo complex does not give rise to the $g=4.3$ resonance observed by EPR.

We have studied X-band EPR spectra of $\mathbf{1 b}$ in the temperature range from 2 to $30 \mathrm{~K}$. The spectra exhibit an intense signal centered at $g=4.3$ and two "absorption-type" features near $g \approx 8$ and $g \approx 5.6$; the latter two features have ca. $12 \mathrm{mT}$ width. The three features observed in the EPR spectrum are associated with (different) excited state Kramers doublets. Figure 10 shows an energy level diagram for an $S$ $=5 / 2$ spin for $D<0$ and $E / D=0.11$; computed effective $g$ values are given for each Kramers doublet. As can be seen, the $g$ values observed at $g \approx 8.0$ and 5.6 can be assigned to the upper and middle doublet, respectively. We have simulated the spectrum of Figure 9 by assuming the presence of two high-spin iron(III) species, one with $D<0$ and $E / D$ $=0.11$ and the other with $D>0$ and $E / D=0.29$. The best simulations were obtained when the two species had a concentration ratio of 9:1, in excellent agreement with the Mössbauer data. In order to obtain the correct width of the $g=8.0$ and 5.6 resonances, the parameter $E / D$ was assumed to have a Gaussian distribution around a mean $E / D=0.11$ with $\sigma_{E / D}=0.05$. The dotted line in Figure 9 is a spectral simulation for the $E / D=0.11$ species. The spin Hamiltonian of eq 3 predicts resonances at $g=3.45$ and 1.66 for the upper Kramers doublet and $g=2.47$ and 2.25 for the middle doublet. A plot of the effective $g$ values vs $E / D$ shows that the aforementioned $g$ values depend strongly on $E / D$, and the associated resonances would thus be so broad that they would not be resolved for a distribution with $\sigma_{E / D}=0.05$. The solid lines in Figure 8 are spectral simulations using the parameters listed in Table 2. For the spectrum of Figure $8 \mathrm{~B}$ we have assumed a Gaussian distribution of $E / D$ values with $\sigma_{E / D}=0.05$; the spectra $\mathrm{A}$ and $\mathrm{C}$ of Figure 8 are insensitive to such a distribution. 


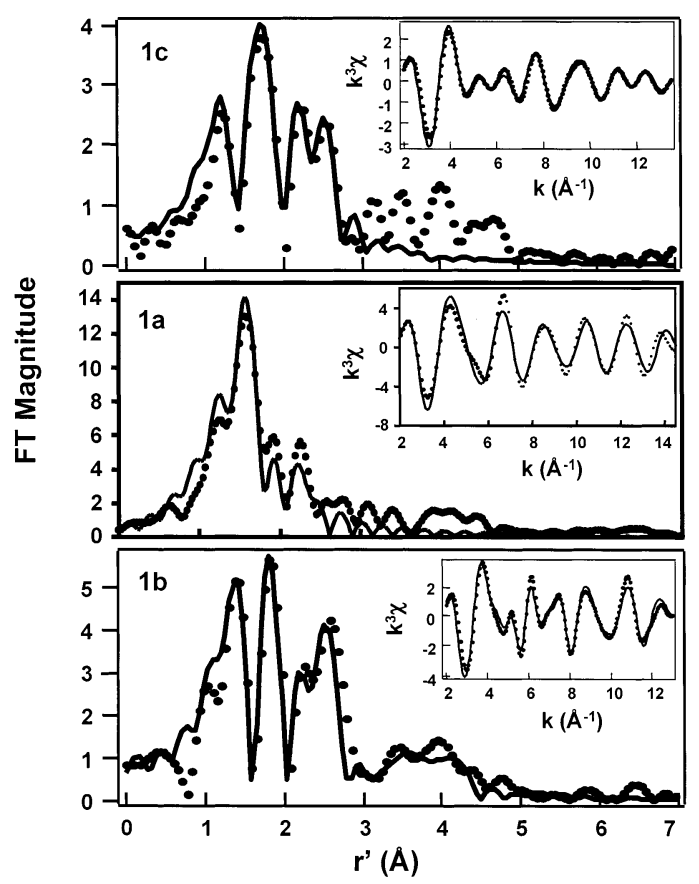

Figure 11. EXAFS analysis of 1a (middle), 1b (bottom), and 1c (top).

Table 2 shows that the parameters extracted from the analysis of data for $\mathbf{1 b}$ resemble those of other $\eta^{2}$-peroxoiron(III) complexes. ${ }^{31,40,57}$ The $\delta$ values (range $0.61-0.67 \mathrm{~mm} /$ s) are somewhat higher than is typical for a high-spin iron(III) center and appear to be a signature for side-on peroxo coordination. Such larger $\delta$ values are also associated with some $\left(\mu\right.$-1,2-peroxo)diiron(III) complexes, ${ }^{61,62}$ but other $(\mu$ 1,2-peroxo)diiron(III) complexes have isomer shifts in the normal range for high-spin iron(III) centers. ${ }^{63-65}$ The electronic basis for the increased $\delta$ values in these complexes is not currently understood.

EXAFS Analysis. EXAFS studies of $\mathbf{1 a}$ and $\mathbf{1 b}$ (Figure 11) provide metrical parameters for the iron ligand coordination environments that support the structural models proposed in Scheme 2. To serve as a foundation for the analysis of $\mathbf{1 a}$ and $\mathbf{1 b}$, an EXAFS study of the structurally characterized $[\mathrm{Fe}(\mathrm{N} 4 \mathrm{Py}) \mathrm{OMe}]\left(\mathrm{ClO}_{4}\right)_{2}$ (1c) was also carried out. The $r^{\prime}-$ space spectrum of 1c (Figure 11, top) exhibits prominent features centered at $r^{\prime}=1.2,1.7,2.2$, and $2.5 \AA$, where $r^{\prime}$ corresponds to the actual metal-scatterer distance $r$ after a phase shift correction of approximately $0.4 \AA$, i.e., $r \sim r^{\prime}+$ 0.4 . Table 3 summarizes the fitting protocol for $\mathbf{1 c}$; the best fit for the $k$-space data (fit 6, Table 3 ) is shown in the inset of Figure 11, top. A single-shell fit of low- $Z$ atoms for the first coordination sphere affords an unreasonably large Debye-Waller factor for the shell (fit 1). Splitting this shell

(61) Kim, K.; Lippard, S. J. J. Am. Chem. Soc. 1996, 118, 4914-4915.

(62) Ookubo, T.; Sugimoto, H.; Nagayama, T.; Masuda, H.; Sato, T.; Tanaka, K.; Maeda, Y.; Okawa, H.; Hayashi, Y.; Uehara, A.; Suzuki, M. J. Am. Chem. Soc. 1996, 118, 701-702.

(63) Ménage, S.; Brennan, B. A.; Juarez-Garcia, C.; Münck, E.; Que, L., Jr. J. Am. Chem. Soc. 1990, 112, 6423-6425.

(64) Dong, Y.; Zang, Y.; Shu, L.; Wilkinson, E. C.; Que, L., Jr.; Kauffmann, K.; Münck, E. J. Am. Chem. Soc. 1997, 119, 12683-12684.

(65) Kodera, M.; Taniike, Y.; Itoh, M.; Tanahashi, Y.; Shimakoshi, H.; Kano, K.; Hirota, S.; Iijima, S.; Ohba, M.; Okawa, H. Inorg. Chem. 2001, 40, 4821-4822. into two low- $Z$ subshells at 1.84 and $2.11 \AA$ (fit 2 ) results in a decrease of the goodness-of-fit value (GOF) by half, suggesting the need for more than one shell. Adding another low $Z$ subshell at $1.77 \AA$ (fit 3) further decreases the GOF by $30 \%$ and gives more reasonable Debye-Waller factors. Thus the best fit for the first coordination sphere consists of three subshells at $1.77,1.96$, and $2.14 \AA$. Inclusion of the outer-sphere features results in fit 6 with additional shells of $2 \mathrm{C}$ at $2.81 \AA$ and $3 \mathrm{C}$ at $2.98 \AA$.

The EXAFS analysis of the solid sample of $\mathbf{1 c}$ agrees with its structural and spectroscopic properties reported earlier. ${ }^{25}$ X-ray crystallographic studies of $1 c$ at $173 \mathrm{~K}$ show the presence of two distinct cations in one asymmetric unit cell. Cation A has a high-spin Fe $\mathrm{Fe}^{\mathrm{III}}$ center, while cation $\mathrm{B}$ has a mixture of low-spin and high-spin $\mathrm{Fe}^{\mathrm{III}}$ centers with relatively shorter $\mathrm{Fe}-\mathrm{N}_{\mathrm{N} 4 \mathrm{Py}}$ distances. ${ }^{25}$ However, variable-temperature magnetic susceptibility experiments indicate that cation $\mathrm{B}$ becomes low-spin at temperatures lower than $70 \mathrm{~K}$. Such a spin-transition behavior is confirmed by our EXAFS analyses on data acquired at $10-20 \mathrm{~K}$ from which two distinct $\mathrm{Fe}-\mathrm{N}$ shells are found in the best fit (fit 6). The subshell at $1.95 \AA$ corresponds to an $\mathrm{Fe}-\mathrm{N}$ distance typical for a low-spin $\mathrm{Fe}^{\mathrm{III}}$ complex and can thus be assigned to the $\mathrm{Fe}-\mathrm{N}_{\mathrm{N} 4 \mathrm{Py}}$ bonds of cation B. The subshell at $2.13 \AA$, on the other hand, corresponds to an $\mathrm{Fe}-\mathrm{N}$ distance typical for a high-spin $\mathrm{Fe}^{\mathrm{III}}$ complex and can thus be assigned to the $\mathrm{Fe}-\mathrm{N}_{\mathrm{N} 4 \mathrm{Py}}$ bonds of cation A. Correspondingly, the two carbon shells at 2.81 and $2.98 \AA$ correspond to the $\alpha$ carbons for the pyridines coordinated to the low-spin and high-spin iron centers of cations B and A, respectively. Lastly, the subshell at $1.76 \AA$ can be assigned to the short $\mathrm{Fe}-\mathrm{OMe}$ bond found for both cations $\mathrm{A}$ and $\mathrm{B}$.

The $r^{\prime}$-space spectrum of $\mathbf{1 a}$ is shown in Figure 11 (middle) with the best $k$-space fit (fit 5 , Table 4 ) in the inset. The data can be modeled well with three shells at 1.76, 1.96, and $2.83 \AA$ A. Similar results are also obtained with two other samples (Tables S1 and S2, Supporting Information). The subshell of $5 \mathrm{~N}$ at $1.96 \AA$ corresponds to the nitrogen atoms of N4Py, the $\mathrm{Fe}-\mathrm{N}$ distance being typical for a low-spin $\mathrm{Fe}^{\mathrm{III}}$ center, while the shell of $4 \mathrm{C}$ at $2.83 \AA$ can be assigned to the carbon atoms $\alpha$ to the bound nitrogen atoms of the four pyridine ligands. The $1.76 \AA$ subshell corresponds to the bound oxygen atom of the hydroperoxo moiety, a value that compares with the $1.80 \AA \mathrm{Fe}-\mathrm{O}$ distance derived from a DFT calculation for $\left[\mathrm{Fe}(\mathrm{N} 4 \mathrm{Py})\left(\eta^{1}-\mathrm{OOH}\right)\right]^{2+},{ }^{37}$ the $1.79 \AA$ $\mathrm{Fe}-\mathrm{O}_{\text {methoxy }}$ bond length of $\mathbf{1 c},{ }^{25}$ and the $1.86 \AA \mathrm{Fe}-\mathrm{O}$ distance found for $\left[\mathrm{Fe}\left(\mathrm{S}^{\mathrm{Me} 2} \mathrm{~N}_{4}(\operatorname{tren})\right)\left(\eta^{1}-\mathrm{OOH}\right)\right]^{+}$by EXAFS analysis. $^{22}$ These observations support the assignment of $\mathbf{1 a}$ as $\left[\mathrm{Fe}(\mathrm{N} 4 \mathrm{Py})\left(\eta^{1}-\mathrm{OOH}\right)\right]^{2+}$ and provide the first metrical details for this family of $\mathrm{Fe}^{\mathrm{III}}-\mathrm{OOH}$ complexes. The difference in the $\mathrm{Fe}-\mathrm{O}$ bond lengths of $\mathbf{1 a}$ and $\left[\mathrm{Fe}\left(\mathrm{S}^{\mathrm{Me} 2} \mathrm{~N}_{4}-\right.\right.$ $($ tren $\left.)\left(\eta^{1}-\mathrm{OOH}\right)\right]^{+}$very likely arises from the presence of the monoanionic thiolate ligand in the latter, which would diminish the Lewis acidity of the metal center in the latter complex.

The $r^{\prime}$-space spectrum of $\mathbf{1 b}$ (Figure 11, bottom) is clearly distinct from that of $\mathbf{1 a}$ with prominent features of the former shifted to values $0.2-0.3 \AA$ longer than the corresponding 
Table 3. EXAFS Fits for $\left[\mathrm{Fe}^{\mathrm{III}}(\mathrm{N} 4 \mathrm{Py})(\mathrm{OMe})\right]^{2+}(\mathbf{1 c})$

\begin{tabular}{|c|c|c|c|c|c|c|c|c|c|c|c|c|c|}
\hline \multirow[b]{2}{*}{$\mathrm{fit}^{a}$} & \multicolumn{3}{|c|}{$\mathrm{Fe}-\mathrm{N} / \mathrm{O}$} & \multicolumn{3}{|c|}{$\mathrm{Fe}-\mathrm{N} / \mathrm{O}$} & \multicolumn{3}{|c|}{$\mathrm{Fe}-\mathrm{N} / \mathrm{O}$} & \multicolumn{3}{|c|}{$\mathrm{Fe}-\mathrm{C}$} & \multirow{2}{*}{$\begin{array}{c}\text { GOF } \\
\epsilon^{2} \times 10^{2}\end{array}$} \\
\hline & $n$ & $r(\AA)$ & $\Delta \sigma^{2 b}$ & $\bar{n}$ & $r(\AA)$ & $\Delta \sigma^{2 b}$ & $\bar{n}$ & $r(\AA)$ & $\Delta \sigma^{2 b}$ & $\bar{n}$ & $r(\AA)$ & $\Delta \sigma^{2 b}$ & \\
\hline 1 & & & & 4 & 2.03 & 34 & & & & & & & $4.9^{c}$ \\
\hline 2 & 1 & 1.84 & 6.5 & & & & 2 & 2.11 & 5.9 & & & & $2.7^{c}$ \\
\hline 3 & 0.6 & 1.77 & 1.2 & 1 & 1.96 & 2.8 & 2 & 2.14 & 3.5 & & & & $1.8^{c}$ \\
\hline 4 & 0.6 & 1.77 & -0.1 & 1 & 1.96 & 0.4 & 2 & 2.14 & 2.1 & & & & $5.3^{d}$ \\
\hline 5 & 0.6 & 1.76 & -0.2 & 1 & 1.95 & 0.4 & 2 & 2.14 & 2.3 & 3 & 2.94 & 6.5 & $3.0^{d}$ \\
\hline \multirow[t]{2}{*}{6} & 0.6 & 1.76 & 0.6 & 1 & 1.95 & 1.7 & 2 & 2.13 & 3.0 & 2 & 2.81 & 6.0 & $2.8^{d}$ \\
\hline & & & & & & & & & & 3 & 2.98 & 2.6 & \\
\hline \multirow[t]{2}{*}{$\mathbf{A}^{e}$} & 1 & 1.77 & & & & & 5 & 2.13 & & 5 & 2.94 & & \\
\hline & & & & & & & & & & 6 & 3.08 & & \\
\hline \multirow[t]{2}{*}{$\mathbf{B}^{e}$} & 1 & 1.79 & & 5 & 2.06 & & & & & 5 & 2.86 & & \\
\hline & & & & & & & & & & 6 & 3.01 & & \\
\hline
\end{tabular}

${ }^{a}$ Fits $1-6$ are for fluorescence data $\left(k=2-13.5 \AA^{-1}\right.$, resolution $0.14 \AA$ ). ${ }^{b} \Delta \sigma^{2}$ is in the units $\AA^{2} \times 10^{3} .{ }^{c}$ Back-transformation range $0.5-2.1 \AA$. ${ }^{d}$ Back-transformation range $0.5-2.8 \AA .{ }^{e}$ Parameters from X-ray structures of the two cations of $1 \mathrm{c} .{ }^{25}$

Table 4. EXAFS Fits for $\left[\mathrm{Fe}^{\mathrm{III}}(\mathrm{N} 4 \mathrm{Py})(\mathrm{OOH})\right]^{2+}(\mathbf{1 a})$

\begin{tabular}{|c|c|c|c|c|c|c|c|c|c|c|}
\hline \multirow[b]{2}{*}{$\mathrm{fit}^{a}$} & \multicolumn{3}{|c|}{$\mathrm{Fe}-\mathrm{N} / \mathrm{O}$} & \multicolumn{3}{|c|}{$\mathrm{Fe}-\mathrm{N} / \mathrm{O}$} & \multicolumn{3}{|c|}{$\mathrm{Fe}-\mathrm{C}$} & \multirow{2}{*}{$\begin{array}{c}\text { GOF } \\
\epsilon^{2} \times 10^{4}\end{array}$} \\
\hline & $n$ & $r(\AA)$ & $\Delta \sigma^{2 b}$ & $n$ & $r(\AA)$ & $\Delta \sigma^{2 b}$ & $n$ & $r(\AA)$ & $\Delta \sigma^{2 b}$ & \\
\hline 1 & & & & 6 & 1 & 5.2 & & & & $11.6^{c}$ \\
\hline 2 & & & & & & & & & & $9.9^{\circ}$ \\
\hline 3 & 1 & 1.75 & 0.8 & 5 & 1. & 2. & & & & $7.2^{c}$ \\
\hline 4 & 1 & 1.7 & & 5 & & 2. & & & & $10.0^{d}$ \\
\hline 5 & 1 & 1.76 & 0.5 & 5 & 1.96 & 2.4 & 4 & 2.83 & 7 & $8.7^{d}$ \\
\hline B & 1 & 1.7 & -0 & 5 & & & 4 & 2. & 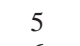 & 8. \\
\hline $\mathrm{C}$ & 1 & 1.77 & -0.6 & 5 & 1.96 & 2.5 & 4 & 2.81 & 6 & $8.7^{d}$ \\
\hline
\end{tabular}

${ }^{a}$ Fits $1-5$ are for a sample that is $90 \%$ 1a based on EPR integration $(k$ $=2-14.5 \AA^{-1}$; resolution $0.13 \AA$ ). Fits $\mathrm{B}$ and $\mathrm{C}$ are best fits for two other samples $\left(k=2-14.5 \AA^{-1}\right)\left(65 \%\right.$ conversion; Tables S1 and S2). ${ }^{b} \Delta \sigma^{2}$ is in units $\AA^{2} \times 10^{3} .{ }^{c}$ Back-transform range $0.5-2.1 \AA$. ${ }^{d}$ Back-transform range $0.5-3.0 \AA$.

Table 5. EXAFS Fits for $\left[\mathrm{Fe}^{\mathrm{III}}(\mathrm{N} 4 \mathrm{Py})(\mathrm{OO})\right]^{+}(\mathbf{1 b})$

\begin{tabular}{|c|c|c|c|c|c|c|c|c|c|c|}
\hline \multirow[b]{2}{*}{$\mathrm{fit}^{a}$} & \multicolumn{3}{|c|}{$\mathrm{Fe}-\mathrm{N} / \mathrm{O}$} & \multicolumn{3}{|c|}{$\mathrm{Fe}-\mathrm{N} / \mathrm{O}$} & \multicolumn{3}{|c|}{$\mathrm{Fe}-\mathrm{C}$} & \multirow{2}{*}{$\begin{array}{c}\text { GOF } \\
\epsilon^{2} \times 10^{4}\end{array}$} \\
\hline & $n$ & $r(\AA)$ & $\overline{\Delta \sigma^{2 b}}$ & $\bar{n}$ & $r(\AA)$ & $\overline{\Delta \sigma^{2 b}}$ & $n$ & $r(\AA)$ & $\Delta \sigma^{2 b}$ & \\
\hline 1 & & & & 3 & 2.08 & 23 & & & & $10.0^{c}$ \\
\hline 2 & 2 & 1.93 & 4.0 & 3 & 2.20 & 4.1 & & & & $2.7^{c}$ \\
\hline 3 & 2 & 1.93 & 4.0 & 3 & 2.20 & 3.8 & & & & $8.9^{d}$ \\
\hline 4 & 2 & 1.92 & 3.8 & 3 & 2.20 & 4.1 & 5 & 3.05 & 4.2 & $4.6^{d}$ \\
\hline 5 & 2 & 1.92 & 3.8 & 3 & 2.20 & 4.1 & 5 & 3.04 & 4. & $5.7^{e}$ \\
\hline \multirow[t]{3}{*}{6} & 2 & 1.92 & 3.8 & 3 & 2.20 & 4.1 & 6 & 3.04 & 5.7 & $4.9^{e}$ \\
\hline & & & & & & & 4 & 4.14 & 8 & \\
\hline & & & & & & & 5 & 4.63 & 7 & \\
\hline \multirow[t]{3}{*}{ B } & 2 & 1.94 & 4.3 & 3 & 2.20 & 3.4 & 6 & 3.04 & 7 & $5.1^{e}$ \\
\hline & & & & & & & 4 & 4.14 & 6 & \\
\hline & & & & & & & 5 & 4.64 & 6 & \\
\hline
\end{tabular}

${ }^{a}$ Fits $1-6$ are for a sample of $\mathbf{1 b}(80 \%$ conversion), and fit B is the best fit for a sample of $\mathbf{1 b}$ with $90 \%$ conversion (Table S3) for data sets with $k$ $=2-13 \AA^{-1}$ (resolution $0.14 \AA$ ). ${ }^{b} \Delta \sigma^{2}$ is in units of $\AA^{2} \times 10^{3} .{ }^{c}$ Backtransform range $0.7-2.1 \AA .{ }^{d}$ Back-transform range $0.7-3.1 \AA .{ }^{e}$ Backtransform range $0.7-4.6 \AA$.

features of the latter. The best fit to the $k$-space spectrum of 1b (fit 6, Table 5) is shown in the inset, while the fitting protocol that led us to this best fit is summarized in Table 5. Similar results are also observed with another sample as shown in Table S3 (Supporting Information). The first coordination sphere is best fit with two low- $Z$ subshells at 1.93 and $2.20 \AA$ (fit 2). It was not possible to introduce a scatterer at $1.8 \AA$ into the fits, suggesting the absence of a short $\mathrm{Fe}-\mathrm{O}$ bond in $\mathbf{1 b}$. The shell of $3 \mathrm{~N} / \mathrm{O}$ at $2.20 \AA$ corresponds to the pyridine nitrogen atoms of N4Py, with the $\mathrm{Fe}-\mathrm{N}_{\mathrm{py}}$ distances typical for a high-spin $\mathrm{Fe}^{\mathrm{III}}$ center. A

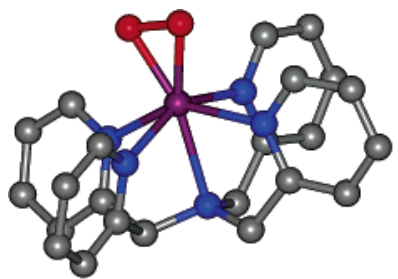

Figure 12. Structure of peroxo complex $\mathbf{1 b}$ based on DFT geometry optimization. Metal-ligand distances $(\AA)$ : $\mathrm{Fe}-\mathrm{O}, 1.96 ; \mathrm{Fe}-\mathrm{N}_{\mathrm{py}}, 2.17$ and $2.27, \mathrm{Fe}-\mathrm{N}_{\text {amine }}, 2.39$.

comparable fit can be obtained with a shell of 4N/O scatterers at $2.20 \AA$ but at the expense of a larger $\Delta \sigma^{2}$ (7 units). More importantly, the shell of $2 \mathrm{~N} / \mathrm{O}$ scatterers at $1.93 \AA$ is assigned to the two oxygen atoms of a side-on bound peroxo moiety. Not surprisingly, this bond distance is somewhat longer than the $\mathrm{Fe}-\mathrm{O}_{\text {peroxo }}$ bond lengths associated with those (average $1.89 \AA$ A) of high-spin iron complexes with end-on peroxo ligands. ${ }^{61,62,66,67}$ The $\mathrm{Fe}-\mathrm{O}$ bond length of $\mathbf{1 b}$ also compares well with the 1.89 and $1.90 \AA$ distances observed for the $\mathrm{Mn}-\mathrm{O}$ bonds in $\left[\mathrm{Mn}(\mathrm{TPP})\left(\eta^{2}-\mathrm{O}_{2}\right)\right]^{-68}$ but is longer than the average $1.86 \AA \mathrm{Mn}-\mathrm{O}$ distance associated with $\left[\mathrm{Mn}^{\mathrm{III}}\right.$ $\left.\left(\mathrm{Tp}^{3,5-\mathrm{iPr} 2}\right)\left(3,5-\mathrm{iPr}_{2} \mathrm{pzH}\right)\left(\eta^{2}-\mathrm{O}_{2}\right)\right]{ }^{69}$ Features in the outer sphere can be fit with carbon scatterers at 3, 4.1, and $4.6 \AA$. These results represent the first structural insights for a synthetic non-heme $\mathrm{Fe}-\eta^{2}-\mathrm{O}_{2}$ complex.

Because no high-resolution X-ray structure of an $\mathrm{Fe}^{\mathrm{III}}-$ $\eta^{2}-\mathrm{O}_{2}$ complex is currently available, we have calculated the metric details of $\mathbf{1 b}$ by geometry optimization using density functional theory. Starting with the X-ray structure of the high-spin site of the methoxy complex $1 \mathbf{c},{ }^{25}$ we replaced the methoxy ligand by an end-on peroxo group and obtained by geometry optimization the structure shown in Figure 12 featuring a seven-coordinate metal center with a side-on peroxo ligand (for atomic coordinates, see Table S4 of the Supporting Information). The $\mathrm{Fe}-\mathrm{O}_{\text {peroxo }}$ bonds optimize at

(66) Dong, Y.; Yan, S.; Young, V. G., Jr.; Que, L., Jr. Angew. Chem., Int. Ed. Engl. 1996, 35, 618-620.

(67) Hashimoto, K.; Nagatomo, S.; Fujiinami, S.; Furutachi, H.; Ogo, S.; Suzuki, M.; Uehara, A.; Maeda, Y.; Watanabe, Y.; Kitagawa, T. Angew. Chem., Int. Ed. 2002, 41, 1202-1205.

(68) VanAtta, R. B.; Strouse, C. E.; Hanson, L. K.; Valentine, J. S. J. Am. Chem. Soc. 1987, 109, 1425-1434.

(69) Kitajima, N.; Komatsuzaki, H.; Hikichi, S.; Osawa, M.; Moro-oka, Y. J. Am. Chem. Soc. 1994, 116, 11596-11597. 
$1.96 \AA$, in good agreement with the $1.93 \AA$ distance for the shorter N/O shell in the EXAFS fit. This structure has a trans pair of $\mathrm{Fe}-\mathrm{N}_{\mathrm{py}}$ bonds of $2.27 \AA$ and another pair with shorter $\mathrm{Fe}-\mathrm{N}$ distances of $2.17 \AA$, the average $\mathrm{Fe}-\mathrm{N}_{\text {py }}$ of $2.22 \AA$ in good agreement with the $2.20 \AA$ distance for the longer N/O shell of 3-4 atoms in the EXAFS fit. The ambiguity in the determination of coordination number by EXAFS is not surprising; the value of 3-4 is well within the uncertainty of EXAFS analysis, ${ }^{43,70}$ as destructive interference between the 2.17 and $2.27 \AA$ subshells would be expected to decrease the amplitude of the $2.20 \AA$ component in the EXAFS analysis. The $\mathrm{Fe}-\mathrm{N}_{\text {amine }}$ distance is calculated to be $2.39 \AA$, but it is not surprising that such a shell does not appear in the EXAFS analysis. Due to the weakness of the $\mathrm{Fe}-\mathrm{N}_{\text {amine }}$ bond, its contribution to the EXAFS spectrum would not be large enough to significantly improve the GOF value of a fit that includes this shell. The DFT calculations for $\mathbf{1 b}$ are thus fully consistent with the EXAFS analysis.

The calculated structure for $\mathbf{1 b}$ is similar to that found crystallographically for $\left[\mathrm{Mn}(\mathrm{TPP})\left(\eta^{2}-\mathrm{O}_{2}\right)\right]^{-68}$ and presumed for its $\mathrm{Fe}$ analogue ${ }^{40}$ with the exception of the weak seventh bond in $\mathbf{1 b}$. For these structures, the $\eta^{2}$-peroxo group sits above a tetragonal plane of four nitrogen ligands and is oriented such that the two oxygens eclipse the two nitrogen atoms; in $\mathbf{1 b}$, they are coplanar with the two longer $\mathrm{Fe}-\mathrm{N}_{\mathrm{py}}$ bonds. The side-on peroxo ligand pulls the iron(III) center out of the plane defined by the four pyridine nitrogens by $0.658 \AA$, compared to $0.764 \AA$ for $\left[\mathrm{Mn}(\mathrm{TPP})\left(\eta^{2}-\mathrm{O}_{2}\right)\right]^{-} .68$ However, the structure calculated for $\mathbf{1 b}$ differs significantly from that proposed by Neese et al. for $\left[\mathrm{Fe}(\mathrm{EDTA})\left(\eta^{2}-\mathrm{O}_{2}\right)\right]^{3-}$ derived from a detailed spectroscopic analysis. ${ }^{39}$ The latter is proposed to have a six-coordinate $\mathrm{Fe}(\mathrm{III})$ center with two of four carboxylates of EDTA dissociated from the metal center. The rather long $\mathrm{Fe}-\mathrm{N}_{\text {amine }}$ distance calculated for $\mathbf{1 b}$ may indicate a similar tendency toward a six-coordinate structure, but the complete dissociation of the amine ligand may be constrained by the N4Py ligand. Furthermore the iron(III) center in $\mathbf{1 b}$ is clearly more Lewis acidic than that in $\left[\mathrm{Fe}(\mathrm{EDTA})\left(\eta^{2}-\mathrm{O}_{2}\right)\right]^{3-}$ and thus less likely to undergo ligand dissociation.

\section{Summary and Perspective}

In this paper, we have described a series of low-spin $\mathrm{Fe}^{\mathrm{III}}-$ $\eta^{1}$-OOH complexes and compared some of their properties. We have also presented a detailed spectroscopic study of $\left[\mathrm{Fe}(\mathrm{N} 4 \mathrm{Py})\left(\eta^{1}-\mathrm{OOH}\right)\right]^{2+}(\mathbf{1 a})$ and its conjugate base $[\mathrm{Fe}-$ $\left.(\mathrm{N} 4 \mathrm{Py})\left(\eta^{2}-\mathrm{OO}\right)\right]^{+}(\mathbf{1 b})$. Since crystal structures of such complexes have not been reported, the EXAFS analyses of 1a and $\mathbf{1 b}$ provide the first metrical details of the iron coordination spheres for this family of complexes with pentadentate N5 ligands.

Complex 1a has a low-spin iron(III) center with a strong $\mathrm{Fe}-\mathrm{OOH}$ bond, as indicated by its $1.76 \AA \mathrm{Fe}-\mathrm{O}$ distance and high $v(\mathrm{Fe}-\mathrm{O})$, and a relatively weak $\mathrm{O}-\mathrm{O}$ bond.

(70) Scott, R. A. In Physical Methods in Bioinorganic Chemistry. Spectroscopy and Magnetism; Que, L., Jr., Ed.; University Science Books: Sausalito, CA, 2000; Chapter 9.
Examination of the $\mathrm{Fe}-\eta^{1}-\mathrm{OOH}$ complexes of a series of related N5 ligands (Table 1 and Figure 3) shows that the more electron rich N5 ligands cause a blue shift of the hydroperoxo-to-iron(III) charge-transfer transition and a decrease of the $\mathrm{O}-\mathrm{O}$ stretching frequency. In line with DFT calculations, ${ }^{35-37}$ the low-spin iron(III) center plays a role in weakening the $\mathrm{O}-\mathrm{O}$ bond and priming it for homolysis prior to substrate attack, a reactivity documented for $\mathbf{1 a} .{ }^{71}$

Comparison of 1a with activated bleomycin reveals major spectroscopic differences between the two complexes. First of all, the quadrupole splittings of both complexes (Table 2) differ substantially, and analysis of the $g$ values with the Griffith model indicates that $\Delta / \lambda \approx 12$ for 1 a compared to $\Delta / \lambda \approx 8.74^{20}$ for activated bleomycin. Second, 1a has an intense HOO-to-Fe(III) charge-transfer band in the visible region, while that for activated bleomycin is much weaker. ${ }^{17}$ Third, 1a has a noticeably shorter $\mathrm{Fe}-\mathrm{OOH}$ bond than activated bleomycin $(1.76$ vs $\geq 1.83 \AA) .{ }^{72}$ Such differences are due to the presence of the monoanionic amidate in the N5 ligand environment of bleomycin, which dominates the metal-ligand interactions. ${ }^{72}$ As a result, activated bleomycin would be expected to have a stronger $\mathrm{O}-\mathrm{O}$ bond than 1a and utilize a somewhat different mechanism for substrate oxidation. Indeed there is a 2 -fold difference in the magnitudes of the deuterium isotope effects for $\mathrm{C}-\mathrm{H}$ bond cleavage by $\mathbf{1}$ and bleomycin. An isotope effect of $\sim 2$ is observed for $\mathbf{1}$ in the oxidation of cyclohexane, reflecting a mechanism involving $\mathrm{O}-\mathrm{O}$ bond homolysis to generate $\mathrm{HO}^{*}$ prior to $\mathrm{C}-\mathrm{H}$ bond cleavage. ${ }^{71}$ In contrast, a deuterium isotope effect of $\sim 4$ is observed for BLM, implicating a metal-centered oxidant in the cleavage of the ribose $\mathrm{C}^{\prime}-\mathrm{H}$ bond in the course of DNA oxidation. ${ }^{73}$ It has thus been proposed that the $\mathrm{Fe}^{\mathrm{III}}-\mathrm{OOH}$ moiety of activated BLM directly attacks the ribose ring and undergoes $\mathrm{O}-\mathrm{O}$ bond homolysis as the $\mathrm{C}-\mathrm{H}$ bond is cleaved. ${ }^{17}$

Complex 1b, on the other hand, has a high-spin iron(III) center with a side-on bound peroxo ligand, as indicated by the presence of two $\mathrm{Fe}-\mathrm{O}$ bonds at $1.93 \AA$ and a diagnostic ${ }^{16} \mathrm{O}^{18} \mathrm{O}$ Raman pattern. Examination of the reactivity of $\mathbf{1 b}$ toward organic substrates has shown that this form is relatively inert compared to its conjugate acid. ${ }^{38,71} \mathrm{~A}$ similar inertness has been noted for $\left[\mathrm{Fe}(\mathrm{EDTA})\left(\eta^{2}-\mathrm{O}_{2}\right)\right]^{3-} \cdot{ }^{39} \mathrm{~A}$ sideon peroxoiron(III) species has been postulated in the mechanism of arene cis-dihydroxylation by the Rieske dioxygenases ${ }^{4,74}$ and recently observed in the crystal structure of a ternary enzyme-substrate $-\mathrm{O}_{2}$ complex of naphthalene dioxygenase..$^{5 \mathrm{~b}}$ If such a species were to be involved in the enzyme mechanism, the lack of oxidative reactivity of corresponding biomimetic complexes suggests that such a species may require subsequent activation, perhaps by protonation, to effect substrate oxidation, as also proposed

(71) Roelfes, G.; Lubben, M.; Hage, R.; Que, L., Jr.; Feringa, B. L. Chem. Eur. J. 2000, 6, 2152-2159.

(72) Westre, T. E.; Loeb, K. E.; Zaleski, J. M.; Hedman, B.; Hodgson, K. O.; Solomon, E. I. J. Am. Chem. Soc. 1995, 117, 1309-1313.

(73) Stubbe, J.; Kozarich, J. W. Chem. Rev. 1987, 87, 1107-1136.

(74) Ballou, D. P.; Batie, C. In Oxidases and Related Redox Systems; King, T. E., Mason, H. S., Morrison, M., Eds.; Alan R. Liss: New York, 1989; pp 211-226. 
for heme enzymes. ${ }^{33,34}$ Indeed Chen et al. have found the first iron catalysts for the cis-dihydroxylation of olefins and proposed the participation of $\mathrm{Fe}^{\mathrm{III}}-\eta^{2}-\mathrm{OOH}$ species in these reactions. ${ }^{75,76}$

Another example of an iron-peroxo intermediate observed in a non-heme enzyme is that associated with superoxide reductase (SOR), the enzyme responsible for converting superoxide to $\mathrm{H}_{2} \mathrm{O}_{2}$ in anaerobes. The reaction of reduced SOR with superoxide engenders a transient absorption band at $600 \mathrm{~nm}$ that is postulated to arise from an iron(III)-peroxo intermediate, but its short lifetime has thus far precluded further spectroscopic characterization. ${ }^{6,7}$ A closely related but longer lived species has recently been generated from the reaction of $\mathrm{H}_{2} \mathrm{O}_{2}$ with E47A SOR. EPR and Raman evidence strongly suggests that this species is a high-spin iron(III)peroxo complex, and an $\eta^{2}$-peroxo binding mode is proposed on the basis of the absence of a $\mathrm{D}_{2} \mathrm{O}$ effect on the Raman vibrations. ${ }^{9}$ However, the Raman data are not fully consistent with an $\eta^{2}$-peroxo binding mode on the basis of the available data on such complexes (Table 1). This species has a low $v(\mathrm{Fe}-\mathrm{O})$, even lower than that of $\left[\mathrm{Fe}(\mathrm{EDTA})\left(\eta^{2}-\mathrm{O}_{2}\right)\right]^{3-}$, but its $v(\mathrm{O}-\mathrm{O})$ is $34 \mathrm{~cm}^{-1}$ higher, more in the range of the $\mathrm{Fe}^{\mathrm{III}}-$ $\mathrm{OOH}$ unit of oxyhemerythrin. ${ }^{54}$ An alternative $\eta^{1}-\mathrm{O}_{2}$ binding mode, for which there is not yet a synthetic precedent, cannot be excluded at the present time. This is a notion supported by recent DFT calculations on the SOR active site, ${ }^{77}$ so there is a need for the definitive mixed ${ }^{18} \mathrm{O}$-isotope experiment to be carried out.

(75) Chen, K.; Que, L., Jr. Angew. Chem., Int. Ed. 1999, 38, 2227-2229.

(76) Chen, K.; Costas, M.; Kim, J.; Tipton, A. K.; Que, L., Jr. J. Am. Chem. Soc. 2002, 124, 3026-3035.
In summary, we have presented a comprehensive spectroscopic study of the $\left[\mathrm{Fe}(\mathrm{N} 4 \mathrm{Py})\left(\eta^{1}-\mathrm{OOH}\right)\right]^{2+}(\mathbf{1 a}) /[\mathrm{Fe}-$ $\left.(\mathrm{N} 4 \mathrm{Py})\left(\eta^{2}-\mathrm{OO}\right)\right]^{+}(\mathbf{1 b})$ pair of iron peroxo complexes. Short of crystal characterization, we have gained insights into their structural and electronic properties. This study provides a basis with which to understand the physical properties of corresponding peroxo intermediates in the catalytic cycles of dioxygen activating iron systems in biology.

Acknowledgment. This work was supported by Unilever Research Vlaardingen (G.R., R.H., and B.L.F.), the Netherlands Ministry of Economic Affairs through the IOP Catalysis program (R.M. la C. and B.L.F.), the U.S. National Institutes of Health (GM-33162 to L.Q. and GM-22701 to E.M.), and the Netherlands Foundation for Chemical Sciences $(\mathrm{CW})$ with financial aid from the Netherlands Organization for Scientific Research (NWO) (A.L.S.). XAS data were collected on beam line X9B at the National Synchrotron Light Source, which is supported by the U.S. Department of Energy and the NIH Research Resource program.

Supporting Information Available: X-ray crystallographic file for $\left[\mathrm{Fe}(\mathrm{TACNPy} 2)\left(\mathrm{CH}_{3} \mathrm{CN}\right)\right]\left(\mathrm{ClO}_{4}\right)_{2}$ (7) in CIF format and a pdf file providing procedures for the ligand syntheses, Tables $\mathrm{S} 1-\mathrm{S} 3$ detailing EXAFS fits for additional samples of $\mathbf{1 a}$ and $\mathbf{1 b}$, and Table S4 listing the atomic coordinates of $\mathbf{1 b}$ obtained by DFT geometry optimization. This material is available free of charge via the Internet at http://pubs.acs.org.

IC034065P

(77) Silaghi-Dumitrescu, R.; Silaghi-Dumitrescu, I.; Coulter, E. D.; Kurtz, D. M., Jr. Inorg. Chem. 2003, 42, 446-456. 